\title{
Article
}

\section{"In this chambered tumulus were found cleft skulls ...": an assessment of the evidence for cranial trauma in the British Neolithic}

Wysocki, Michael Peter and Schulting, R J

Available at http://clok.uclan.ac.uk/321/

Wysocki, Michael Peter and Schulting, R J (2005) "In this chambered tumulus were found cleft skulls ...": an assessment of the evidence for cranial trauma in the British Neolithic. Proceedings of the Prehistoric Society, 71 . pp. 107138. ISSN 0079-497X

It is advisable to refer to the publisher's version if you intend to cite from the work. http://dx.doi.org/10.1017/S0079497X00000979

For more information about UCLan's research in this area go to http://www.uclan.ac.uk/researchgroups/ and search for <name of research Group>.

For information about Research generally at UCLan please go to http://www.uclan.ac.uk/research/

All outputs in CLoK are protected by Intellectual Property Rights law, including Copyright law. Copyright, IPR and Moral Rights for the works on this site are retained by the individual authors and/or other copyright owners. Terms and conditions for use of this material are defined in the policies page. 


\title{
'In this Chambered Tumulus were Found Cleft Skulls ...': an Assessment of the Evidence for Cranial Trauma in the British Neolithic
}

\author{
By Rick J. SCHUlting ${ }^{1}$ and Michael WYSOCKI ${ }^{2}$
}

Interpersonal violence is a powerful expression of human social interaction. Yet a consideration of violence in the past has done relatively little to inform our discussions of the British Neolithic. Here, we present the results of an examination of some 350 earlier Neolithic crania from mainly southern Britain. Of these, 31 show healed or unhealed injuries suggestive of interpersonal violence. We suggest a conservative estimate of $2 \%$ fatal cranial injuries, and 4 or $5 \%$ healed injuries. These data are used as a platform to discuss possible contexts for, and consequences of, violence. We argue that, regardless of its actual prevalance, the reality or the threat of interpersonal violence can have an important affect on both the behaviour of individuals and the structure of society.

\section{INTRODUCTION}

The role of violence in the Neolithic period in Britain, and indeed in European prehistory in general, remains poorly understood. With some notable exceptions (eg, Mercer 1999), the tendency has been to downplay or ignore the role of interpersonal violence in structuring both society and individual experience. Such a stance has resonance with Keeley's (1996) argument that archaeologists, largely through omission, have 'pacified' the past (see also Otterbein 1999; Sharples 1991; Thorpe 2003; Vandkilde 2003; Vencl 1984). Materials originating from long distances found on archaeological sites are attributed to trade and exchange, not to warfare and looting. Dismembered human bones and isolated crania in pits and ditches on causewayed enclosures and in mortuary monuments are attributed to ritual behaviour involving the ancestors rather than to acts of violence. Similarly, evidence of burning at the few domestic sites

\footnotetext{
${ }^{1}$ School of Archaeology and Palaeoecology, Queen's University Belfast, Belfast BT7 1NN (e-mail: r.schulting@qub.ac.uk)

${ }^{2}$ Department of Forensic and Investigative Science, University of Central Lancashire, Preston PR1 3HE (e-mail: mpwysocki@uclan.ac.uk)
}

Received: March 2004; Accepted July 2004 with structures that are known is usually treated as either accidental or ritual (for an exception, see Logue 2003). In many cases these interpretations may be perfectly valid, but it seems that what is lacking is at least a consideration of the alternatives. Ethnographic and historic accounts document the prevalence and importance of interpersonal violence and warfare even in small-scale societies (Keeley 1996; Ember \& Ember 1997; Haas \& Creamer 1997; Otterbein 1968). There is no reason to think that it was otherwise in prehistory. A major stumbling block to a fuller consideration by British prehistorians of warfare and interpersonal violence in general has been a perceived lack of evidence. Through an analysis of earlier Neolithic human crania, we hope to show here that this lack is more perceived than real.

Interpersonal violence may take many forms, from domestic violence, assault, homicide, or punishment beatings/executions within the community, to raiding and warfare against outsiders, however the latter are defined. The most dramatic of these falls under the general classification of 'warfare'. As an exception to the general trend noted above, the last 15 years or so have seen something of a resurgence of interest in the documentation and interpretation of evidence for warfare in the British Neolithic. For the most part, however, the focus has been limited to the debate over whether or not causewayed enclosures served a 
defensive function. The sites dominating discussion are Hambledon Hill, Dorset (Mercer 1980; 1988), Crickley Hill, Gloucestershire (Dixon 1988), Hembury Hill, Devon (Liddell 1935; Mercer 1990), and the hill top enclosures of Carn Brea and Helman Tor, Cornwall (Mercer 1986; 1989a, b). These sites show convincing evidence of a defensive function; indeed their defences appear to have been tested at some points in their history, and, in the case of Hambledon Hill and Crickley Hill, found wanting. A $200 \mathrm{~m}$ section of the Stepleton enclosure at Hambledon Hill appears to have been attacked and fired, and in its collapse were found the remains of two young adult males, both of whom were apparently shot with arrows, although the points are not actually embedded (Mercer 1999, 154). The remains of an additional four individuals may be linked to the same event (Mercer 1988, 104). The entrances to some of these sites were found strewn with leaf-shaped arrowheads, some 800 at Carn Brea, more than 400 at Crickley Hill, and more than 140 in limited excavations at Hembury. Intense burning featured at all three sites, and many of the arrowheads were calcined. Unfortunately bone preservation was poor.

A number of other enclosures have been put forward as possible defensive sites: eg, Abingdon, Oxfordshire (Bradley 1986), Haddenham, Cambridgeshire (Hodder 1990, 260), Maiden Castle, Dorset (Sharples 1991), and, in Northern Ireland, Lyles Hill (Gibson \& Simpson 1987) and Donegore (Mallory \& Hartwell 1984), both in Co. Antrim. In general, however, the consensus is that the majority of British causewayed enclosures are both poorly situated and poorly designed to have functioned primarily as defended places (Bradley 1984; 1998; Oswald et al. 2001; Whittle 1977; 1996), though this is not to say that they were never used as such as the occasion arose.

Studies that have addressed the skeletal evidence for interpersonal violence in the British Neolithic have focused almost exclusively on projectile trauma (eg, Edmonds \& Thomas 1987; Green 1980; Mercer 1999). The few earlier Neolithic sites with embedded projectile points are Ascott-under-Wychwood, Oxfordshire (Selkirk 1971), Tulloch of Assery B, Caithness (Corcoran 1967), and, in Ireland, Poulnabrone, Co. Clare (Lynch 1988; Lynch \& Ó Donnabháin 1994). The most recent addition to this short list is the tip of a leaf-shaped point found embedded in a human rib from the Penywyrlod shambered tomb, Powys (Wysocki \& Whittle 2000).
In a much larger number of cases - eg, Cat's Water, Fengate, Cambridgeshire (Pryor 1976), Hambledon Hill, Dorset (Mercer 1988; 1999), Wayland's Smithy, Oxfordshire (Atkinson 1965), West Kennet, Wiltshire (Piggott 1962), Wor Barrow, Dorset (Pitt-Rivers 1898), and others - the position of a projectile point vis-à-vis the body suggests penetration, but until this material is re-examined for diagnostic traces, these examples remain tentative, if suggestive.

And this is the main problem with assessing the projectile point evidence. Points embedded in bone are likely to be the exception rather than the rule, as the intent is to penetrate soft tissues, not to hit bone. Experimental archaeology has shown that a flinttipped arrow fired by a Neolithic bow could pass completely through a medium-sized animal, or a human, at a distance of 15-25 m (Coles 1977, 55). At a Final Palaeolithic Nubian cemetery with abundant evidence for interpersonal violence, only about $25 \%$ of those individuals with what were identified as arrow wounds actually exhibited embedded fragments of stone (Wendorf 1968; though this statistic is itself open to some debate - Jurmain 2001, 20). This is no doubt one reason that violence has been often underestimated in archaeological contexts. Mercer's (1999) arguments regarding the greater suitability of the leaf-shaped arrowhead for killing humans rather than game are germane here, particularly in light of the scarcity of wild fauna on Neolithic sites (see also Case in C. Green et al. 1970, 111; Green 1980, 166, 179; Saville 2002, 96). Not all leaf-shaped arrowheads - and Green (1980, table iv) documents 136 earlier Neolithic examples from funerary contexts - found with human remains need be grave offerings (Wysocki \& Whittle 2000), particularly those with snapped off tips, suggestive of high velocity impact.

Yet while both the architectural evidence and projectile points represent important approaches to interpersonal violence, they represent an unduly restricted treatment of the potential range of evidence, and in particular the skeletal evidence itself. While a number of reports deal with skeletal trauma at a sitespecific level (Brothwell \& Blake 1966; McKinley forthcoming; Rogers 1990), there has been little attempt to re-examine earlier collections, or to synthesise all the available information. Only through analysis of the full complement of existing skeletal collections will a fuller understanding of the extent and context of interpersonal violence emerge. Here, expanding upon an earlier brief communication 


\section{R. Schulting and M.Wysocki EVIDENCE FOR CRANIAL TRAUMA IN THE BRITISH NEOLITHIC}

(Schulting \& Wysocki 2002), we offer as a contribution towards this goal the results of an ongoing re-assessment of human skeletal material from the British earlier Neolithic, c. 4000-3200 cal $\mathrm{BC}$. We concentrate on cranial trauma, for three reasons. First, from a practical standpoint, many of the extant collections consist predominantly of crania. Secondly, the individual diagnosis of postcranial perimortem trauma in disarticulated and fragmented material is highly problematic (Villa \& Mahieu 1991). Finally, this class of evidence provides a different perspective from the 'violence at a distance' seen with projectile injuries. Of course, there are many contexts for violence, within communities as well as between communities, and of lethal and non-lethal intent, and discussion also touches upon the difficult issue of possible ways of distinguishing these. Finally, an attempt is made to consider some of the possible consequences of violence, or the threat of violence, for the British Neolithic.

\section{The Mechanics of Cranial Injury}

Nineteenth century accounts of investigations into British Neolithic barrows are replete with references to cranial trauma. John Thurnam in particular was prone to describe almost any broken skull as intentionally 'cleft' (eg, Thurnam 1856; 1869, 185). Many of the more graphic accounts are today rightly treated with caution, given the exuberance and relish with which identifications of violence were made in some 19th century reports, and the predisposition of the times to view prehistoric life through a Hobbesian lens as 'nasty, brutish and short'. Thurnam's assessments were questioned even by his contemporaries. Indeed, Rolleston (1876; 1877, 684-90) effectively showed many of Thurnam's examples to be no more than post-depositional or post-excavational breakage. Nonetheless, Thurnam's claims continued to pique the curiosity of later authorities, with Crawford (1925, 26, later echoed by Piggott 1954, 141) suggesting the whole issue be reexamined by a police surgeon. However, despite such urgings little effort has been made to re-analyse the skeletal material in light of advances in our understanding of the mechanics of bone fracturing.

And a re-assessment of the extant material is essential. There must be serious reservations regarding the validity of all identifications of perimortem injury in the literature not accompanied by detailed descriptions and preferably also by high quality images. This particularly applies to early accounts, but can also be a factor in more recent reports, as we note below. While much skeletal material was examined by the foremost experts at the time (eg, Sir Arthur Keith, John Thurnam), both fracture mechanics and taphonomic processes were poorly understood in the 19th and early 20th centuries (and the latter can hardly be said to be fully understood today). For example, most of the early claimed examples of 'cleft' crania that we have re-examined from the Thurnam Collection are nothing of the sort, but simply show post-depositional, dry bone breakage (Fig. 1).

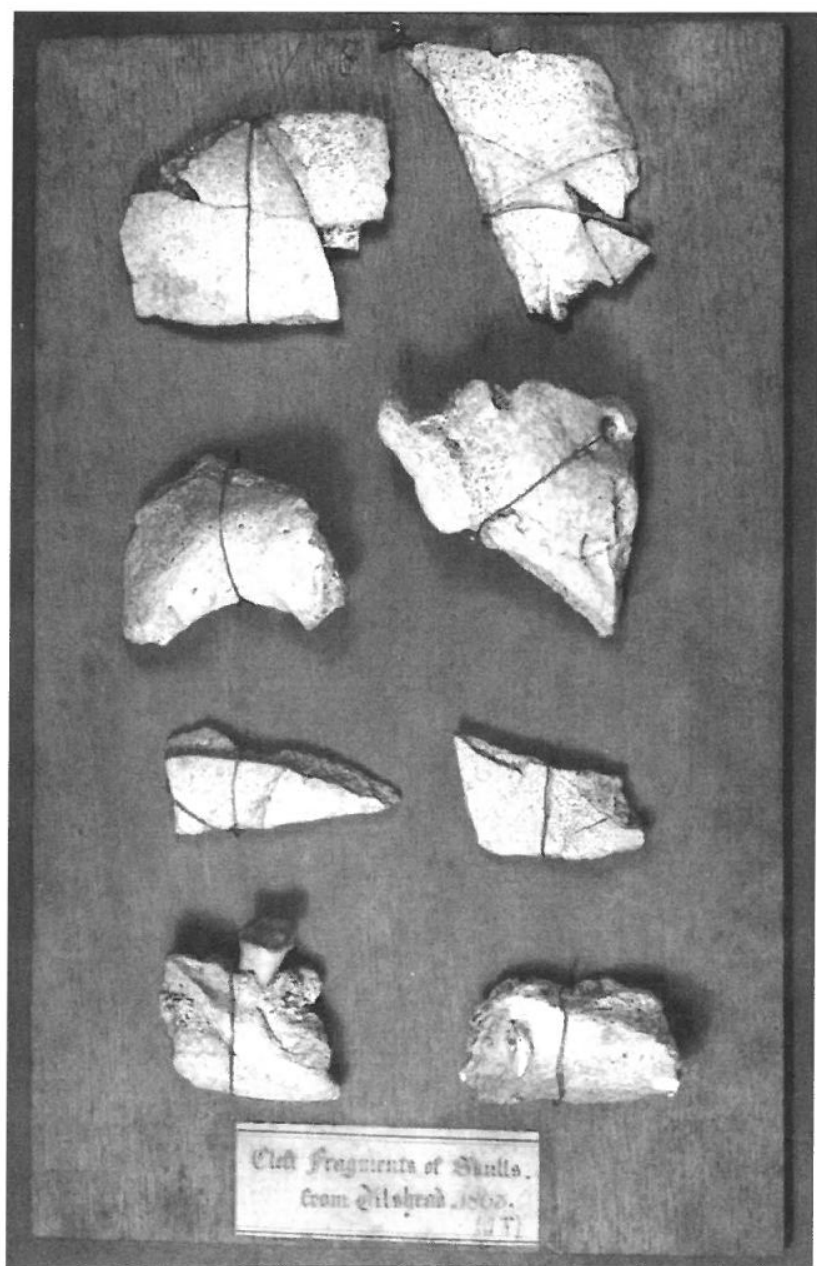

Fig. 1. Cranial fragments from the site of Tilshead (White Barrow), from an early display by John Thurnam of examples of 'cleft' crania. The breaks are all clearly on dry bone, made long after death (Duckworth Collection, Cambridge). 
There are well-defined forensic criteria for the identification of perimortem cranial trauma ('perimortem' refers to injury at or around the time of death, when the bone is still in a 'fresh' state, with fat and moisture content maintaining the tensile strength of living bone - the duration of this period may be highly variable depending on the depositional environment). These criteria include: depressed but still adhering bone on the edges of the injury site, in some cases taking the form of concentric fractures; linear and stellate fractures, the latter radiating out from the point of impact; oblique angles on fracture edges; bevelling or flaking on the inner table of the cranium at the site of impact; and, on occasion, contrecoup fractures to the side of the skull opposite the impact (Smith et al. 2003; Berryman \& Haun 1996; Gurdjian et al. 1950; Kaufman et al. 1997; Knight 1991, 163-70; Lovell 1997, 145; Maples 1986; Ortner \& Aufderheide 1991; Ortner 2003; Ortner \& Putschar 1985; Wakely 1997). An important additional criterion when dealing with archaeological material involves the uniform patination of the fracture surfaces and adjacent bone. When a number of these classic indicators are present, the identification is usually straightforward. But not all indicators need always be present. The problem is compounded when dealing with fragmentary and eroded material, sometimes reconstructed with excessive glue and plaster (an extreme example of which is discussed below).

Finally, it need not be the case that every example of perimortem or healed cranial fracturing refers to interpersonal violence. Blows to the head can occur during falls or other accidents, or even while manoeuvring a recent corpse into a megalithic chamber (either to the corpse or to the bearer). But in the majority of cases it is likely that cranial injuries of the kind that do lead to serious fracturing are the result of intentional violence (though not necessarily always interpersonal; injuries may be self-inflicted, for example as cathartic expressions of grief during mourning rituals; Webb 1995, 202). Clinical data show that accidental falls are more likely to result in linear fractures to the cranium, as the point of impact is usually broader and the force more diffuse than in an intentional blow (Lambert 1997; Lovell 1997). Even a 'blunt' object, such as a club, provides a much more concentrated application of force, resulting in strongly localised trauma such as depressed fractures or complete, and often distinctly rounded, perforations of the cranial vault. Patterning in the location of the injuries, when present, can also help to differentiate the causes of injuries, but this is dependent on the type of conflict. For example, one would expect the majority of head injuries sustained during face to face combat to be located on the left side of the skull, with the mandible, left parietal, and left temporal most frequently affected (Novak 2000, 96). On the other hand, the use of projectiles, whether slings or bows, or even hand-thrown stones, would not necessarily lead to much in the way of patterning.

For a number of the unhealed cranial fractures discussed below, positive diagnosis is admittedly difficult, especially in the absence of one or more classic criteria. Despite this problem, it is essential to take this material into account. We do not advocate, as some researchers have, limiting the study of cranial trauma to only those examples showing healing (eg, Alvrus 1999; M. Smith 2003; Wilkinson \& van Wagenen 1993). While this may minimise the number of questionable cases, it runs the risk of creating a strongly biased view. There may be many different contexts for interpersonal violence, some of which are more likely to lead to lethal injuries than others. Nor is it entirely clear to us that dealing only with examples showing some indication of healing completely circumvents problems of diagnosis. Some very old injuries may be so remodelled that they are difficult to identify. Difficulties in determining the cause of the trauma affect both healed and unhealed examples, although of course with healed examples there is at least no question of post-depositional factors (erosion can cause rounded depressed or perforated areas, but it is usually fairly straight forward for experienced researchers to distinguish these from in vivo processes). Here, we divide examples into high, medium, and low probability categories, with those in the last category excluded from the analysis.

\section{THE CRANIAL INJURIES}

We have examined some 350 'composite' (eg, two halves making a whole) adult and adolescent crania in sufficient condition for a reasonable assessment to be made (Table 1). Dealing with composite crania is less than ideal, but necessary given the nature of the material and the need to put the findings into a population perspective. The facial region, frequently a 


\section{R. Schulting and M. Wysocki EVIDENCE FOR CRANIAL TRAUMA IN THE BRITISH NEOLITHIC}

TABle 1. EARlier NeOlithiC COllections EXAMINED

\begin{tabular}{lll}
\hline Long barrows & Chambered tombs & Other \\
\hline Southern England & Cotswold-Severn & Causewayed enc. \\
Bisley & Belas Knap & Staines \\
Bole's Barrow & Gatcombe & \\
Bredon Hill & Littleton Drew/Lugbury Caves \\
'Dorsetshire' & Parc le Breos Cwm & Cathole \\
Figheldean Down & Penywyrold & Gop \\
Fussell's Lodge & Pipton & Hay Wood \\
Fyfield & Rodmarton & Ifton \\
Giant's Hill & Sale's Lot & Pant y Wennol \\
Lanhill & Swell & Priory Farm \\
'Long Barrow 1870' & Tinkinswood & \\
Norton Bravant & Ty Isaf & River finds \\
Tilshead (White Barrow) & Uley & Preston Docks \\
West Monkton & Wayland's Smithy I & \\
Whiteleaf & Wayland's Smithy II & \\
Winterbourne Monkton & West Kennet & \\
Winterbourne Stoke & West Tump & \\
& & \\
Northern England & Medway & \\
Dinnington & Coldrum & \\
Ebberston & & \\
Rudston & & \\
Whitwell long cairn & & \\
\hline
\end{tabular}

specific target of interpersonal violence in many societies, is only rarely preserved, so that injuries to the face are likely to be under-represented. The project began in part as an effort by one of the authors to reexamine injuries claimed in the literature, but the opportunity was taken at each institution visited to examine all available earlier Neolithic cranial material. While there is thus the possibility of a slight bias exaggerating the number of cases of cranial trauma, we feel that this is balanced by the fact that all available material was examined in the end.

The majority of the collections that have been examined to date are from southern Britain, and most derive from long barrows and the Cotswold-Severn group of chambered tombs (Fig. 2). We have, however, also examined crania from Preston Docks, Dinnington, Ebberston, and other sites in northern England, as well as from a number of cave sites (Table 1). Further work is underway to allow a comparison of the various regions of Britain and Ireland. Few examples have been directly dated, so that their attribution to the earlier Neolithic relies on their context. But the assumption seems justified given the good series of dates that are available for a number of these monuments. Non-monumental contexts are more problematic, and generally rely on direct dating. In the following survey, we focus primarily on material that we have personally examined. The large assemblage of human remains from Hambledon Hill has not been examined by the authors, as it is currently in the process of publication, but a thorough re-analysis of the material has been made (McKinley forthcoming) which is drawn upon here. Nor has the fragmentary material from Hazleton North, Gloucestershire, yet been re-examined, although Rogers (1990) found no cranial injuries in her report on the collection. There are a number of other examples claimed in the literature that are not dealt with here and form the focus of ongoing research (eg, a perimortem cranial fracture reported on an adolescent from Tulloch of Assery B, Caithness (Corcoran 1967), unhealed injuries to an adult male from Duggleby Howe, Yorkshire (Garson 1905), and a well documented healed depressed fracture on an adult male from Poulnabrone, Co. Clare (Lynch 1988; Lynch \& Ó Donnabháin 1994)). Other examples claimed in the literature have not yet been located, and it is likely that a number of specimens have been lost. We divide the discussion into unhealed (perimortem) and healed fractures. In the case of a non-lethal blow, the process of healing begins immediately, and results in discernable changes to the bone after a period of some weeks (Lovell 1997, table 2). Radiography and computer tomography (CT) scans can provide a more accurate assessment of the early stages of healing (Chege et al. 1996), but this remains a task for future research.

\section{Unhealed examples}

One of the best examples of perimortem cranial trauma identified during the study comes from the site of Belas Knap, a classic Cotswold-Severn tomb, coincidentally (or perhaps not) not far from the wellknown defended Neolithic enclosure of Crickley Hill, Gloucestershire (Dixon 1988). Ironically, Thurnam highlighted Belas Knap as one of only two sites (the other being Nympsfield) among the many that he studied in which he had found '... no traces of violent cleavage of the cranial bones' (1869, 227-8). Crawford (1925), on the other hand, identified perimortem cranial trauma on as many as eight individuals from Belas Knap. While admitting to not being an expert in the field, Crawford also expressed surprise at Thurnam's failure to recognise evidence that to his mind was 'clear and convincing' (1925, 25-6). After a re-assessment of the material, there is no doubt that Crawford's claims are exaggerated (Schulting et al. in prep). However, at least two individuals (an adolescent probable female and an 


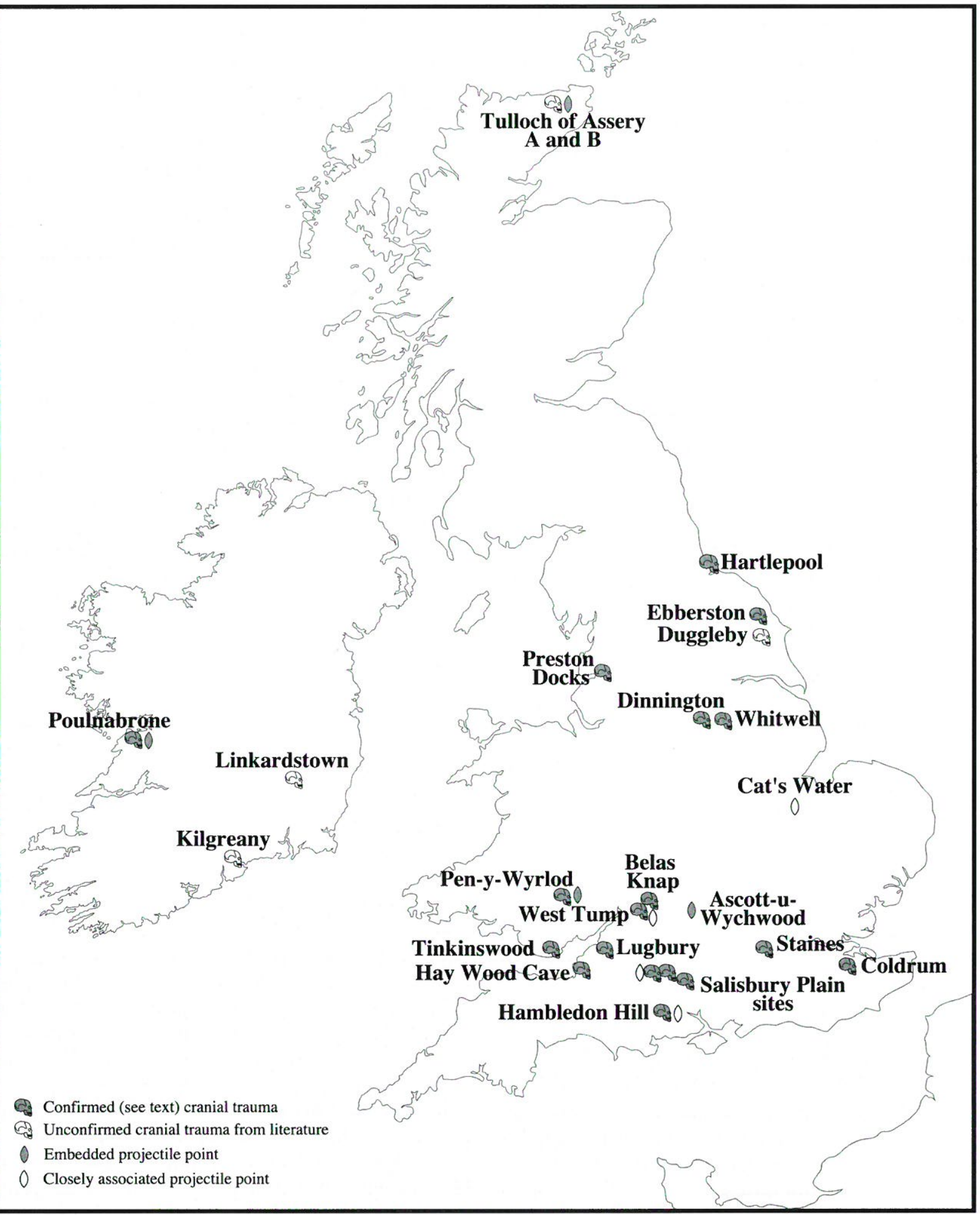

Fig. 2. Map showing sites with evidence of possible interpersonal violence identified in England and Wales, together with sites with cases reported from the literature in Scotland and Ireland. 
adult female) do show good evidence of perimortem trauma, the adolescent in particular showing all the classic features associated with massive blunt-force injury (Fig. 3). The adult female shows a perforating injury with adhering depressed bone on the top of the cranium (Fig. 4). A third individual, an adult male (CIV), exhibits a possible perimortem injury, although it is not entirely convincing, and has been given a 'low probability' rating here (Table 2). Another problematic example of cranial fracture comes from the nearby Cotswold-Severn tomb of West Tump. More secure from this site is a small healed depressed fracture, discussed below.

Coldrum belongs to the rather enigmatic Medway group of megalithic tombs in Kent (Bennett 1913). Three individuals at the site show evidence of trauma, two unhealed and the other healed. A probable adult female shows a well-defined injury to the left frontal (Fig. 5), and another probable injury to the back of the left parietal (see below). The same individual also has two fine parallel cutmarks on the left temporal bone, just above and behind the external auditory meatus (the earhole) (Fig. 6). The cuts are clearly not recent, being patinated and overlain by root etching. They have yet to be examined under high magnification, but are noteworthy in light of the definite stone tool cutmarks previously identified on postcrania from this site (Wysocki and Fernandez-Jalvo in prep.). A small fragment of frontal bone from another Coldrum individual exhibits a probable unhealed fracture with concentric rings and adhering bone above the left orbit; in fact the injury is very similar to that seen in the first Coldrum individual (Fig. 7). This is probably an adult, of indeterminate sex.

An adult male cranium attributable only to a 'Dorsetshire long barrow' exhibits a large unhealed blow to the left parietal. As is the case with the injury to the rear of the left parietal of the adult female from Coldrum, this is a somewhat unusual example, in that bevelling occurs on both the inner and the outer tables of the cranial vault (Fig. 8). Due to their 'figure eight' shape and characteristic opposed inner-outer bevelling pattern, similar injuries to the skull are known as 'keyhole wounds' or 'gutter wounds' in the forensic literature, and are typical of tangential or shallow-angled gunshot wounds (Berryman et al. 1995; DiMaio 1999; Quatrehomme \& Iscan 1999; 1999; Smith et al. 2003), although they may also occur with lower velocity tangential impacts. Linear fractures radiating out from the site of injury further

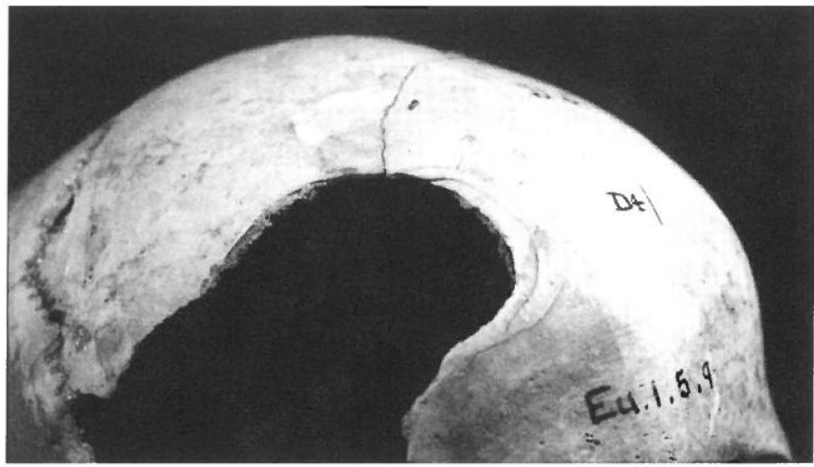

Fig. 3. Belas Knap D-4 adolescent? with massive injury to right parietal (Duckworth Collection, Cambridge)

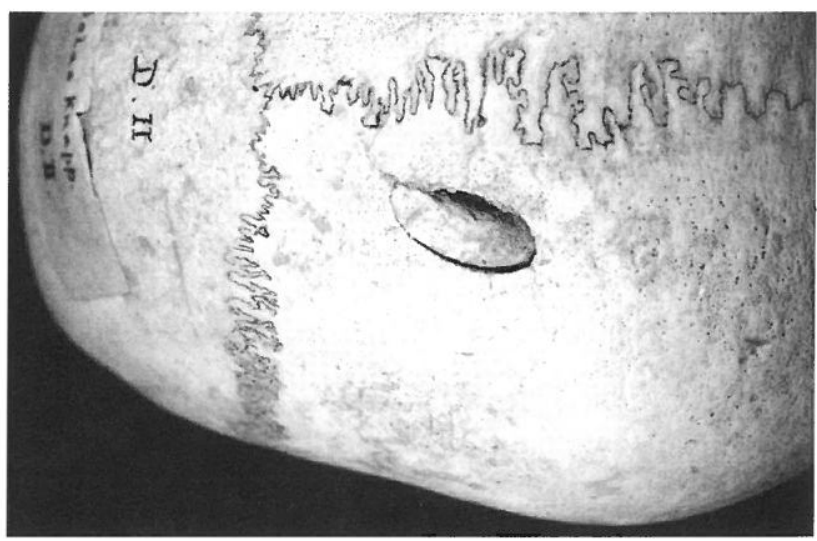

Fig. 4. Belas Knap D-II adult female with an unhealed injury to top of left parietal (Duckworth Collection, Cambridge).

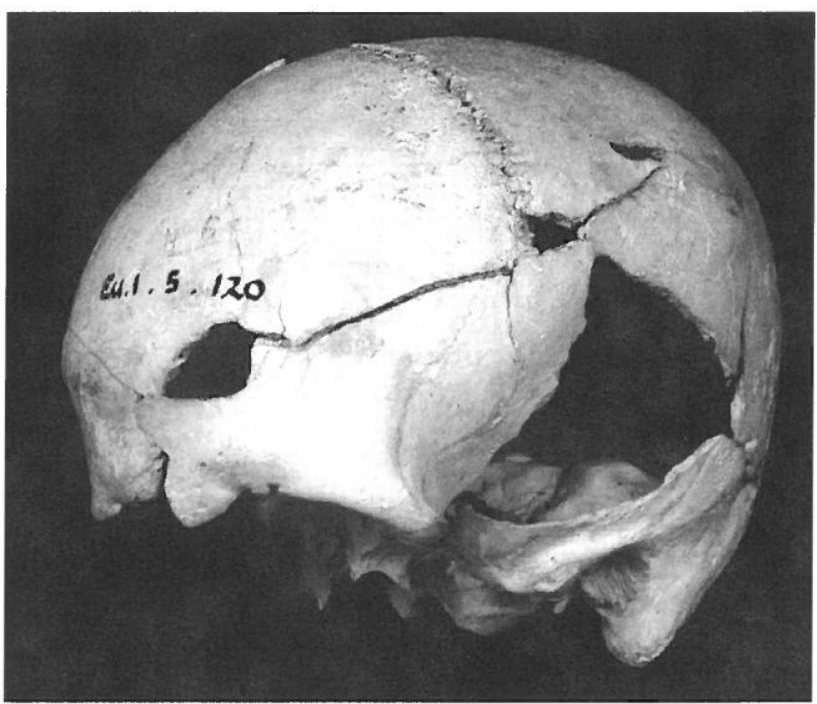

Fig. 5. Coldrum Eu.1.5.120 adult female? showing unhealed injuries to left frontal and parietal (Duckworth Collection, Cambridge). 
THE PREHISTORIC SOCIETY

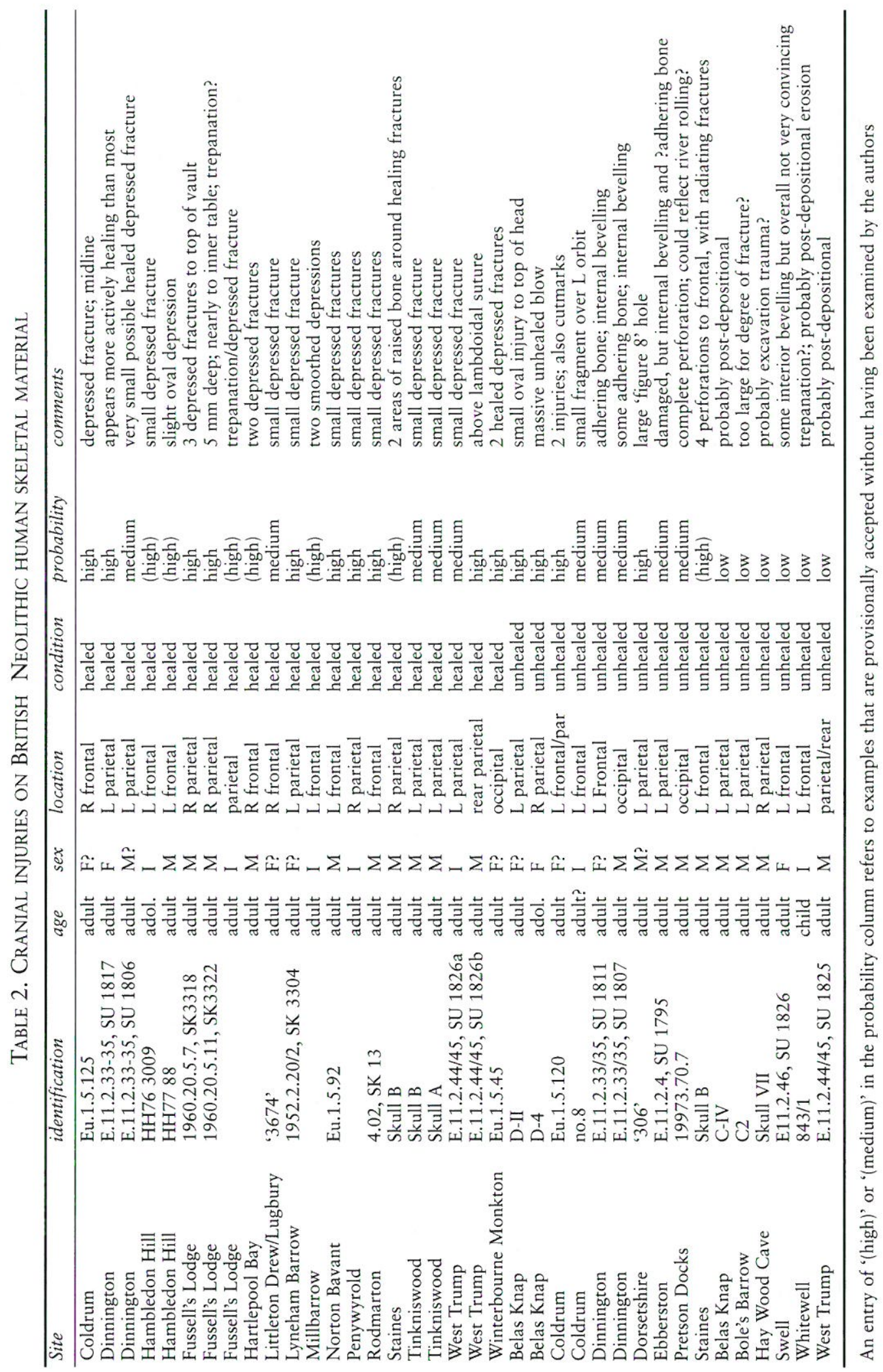




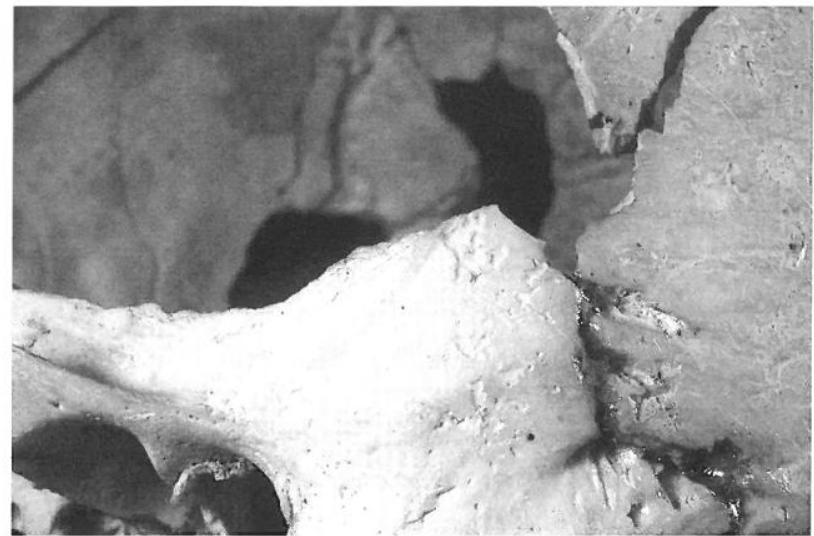

Fig. 6. Coldrum Eu.1.5.120 showing two parallel cutmarks in middle of field (Duckworth Collection, Cambridge).

support the diagnosis of a perimortem blow to the head in the Dorsetshire example (although in the line extending towards the left temporal the edges of the break are perpendicular to the bone surface, a characteristic that tends to be associated with drybone breakage).

Dinnington long barrow (Thurnam 1869) in Yorkshire presents one of the few assemblages from northern England that have been investigated to date.
Crania from some 14 adults were examined, with two showing highly suggestive indications of perimortem trauma (medium probability category in Table 2 ). The first example is on the left frontal of a probable young adult female. The incomplete perforation takes the form of a rounded trapezoid. Adhering depressed bone and interior bevelling are present (Fig. 9). The second example is found on the occipital of an adult male. This injury is represented by a complete perforation of the cranial vault, with a small piece of adhering depressed bone on the left lateral margin (Fig. 10). Interior bevelling and internal radiating fractures are present (Fig. 11). Somewhat less convincing (but still placed within the medium probability category) is an oval perforation to the top of the left parietal of an adult male from Ebberston, Yorkshire (Greenwell 1877, 484-7). Unfortunately the edges of the perforation are damaged postmortem. It does, however, show internal bevelling, and provides a slight indication of adhering depressed bone.

An intriguing collection of some 20 human crania, together with a large number of red deer antlers and cattle horn-cores, comes from the 19th century construction of the Preston Docks, Lancashire (Huddart et al. 1999; Turner et al. 2002). Some of the

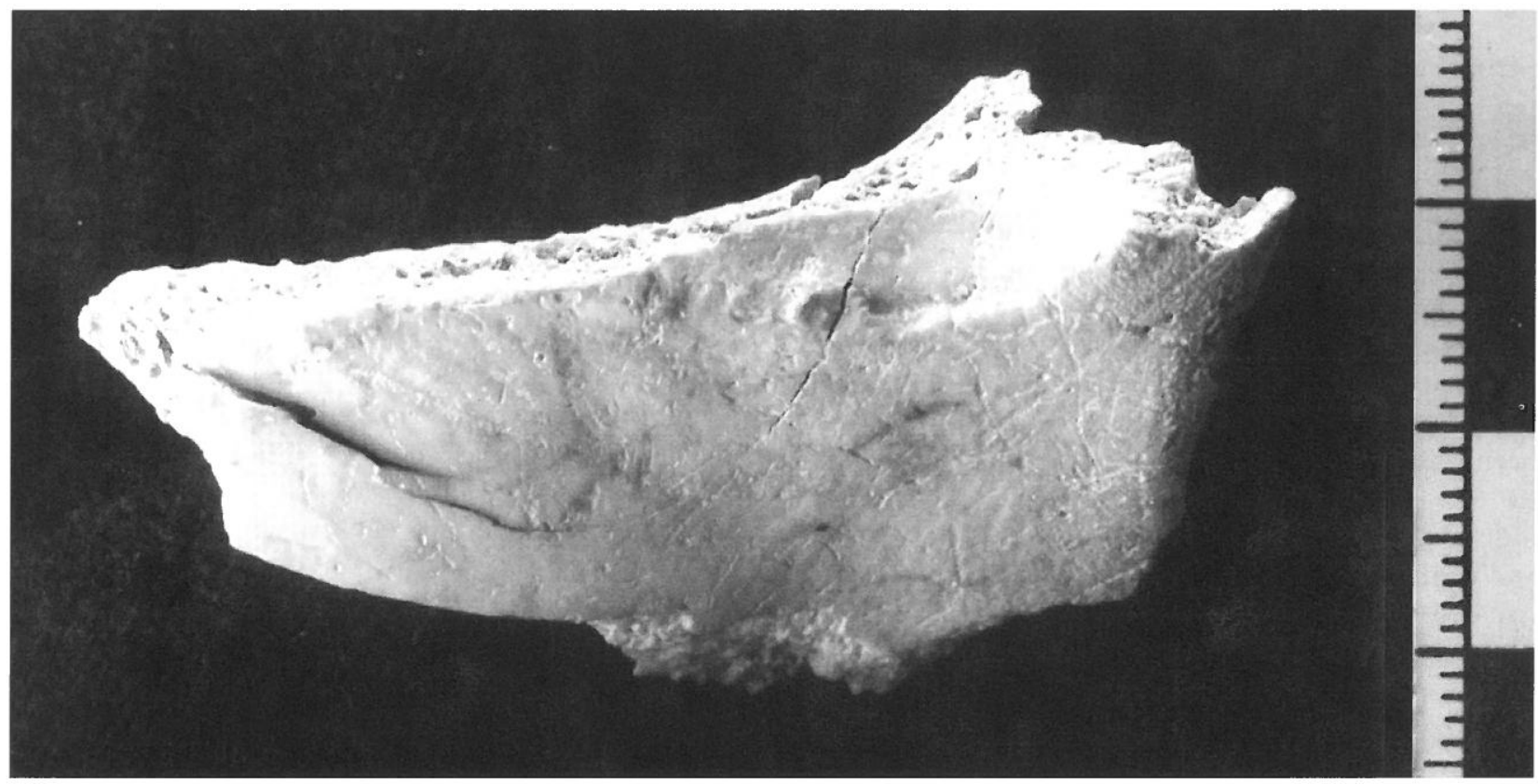

Fig. 7. Coldrum ' 8 ' cranial fragment with an unhealed fracture to left frontal over orbit (Natural History Museum, London). 


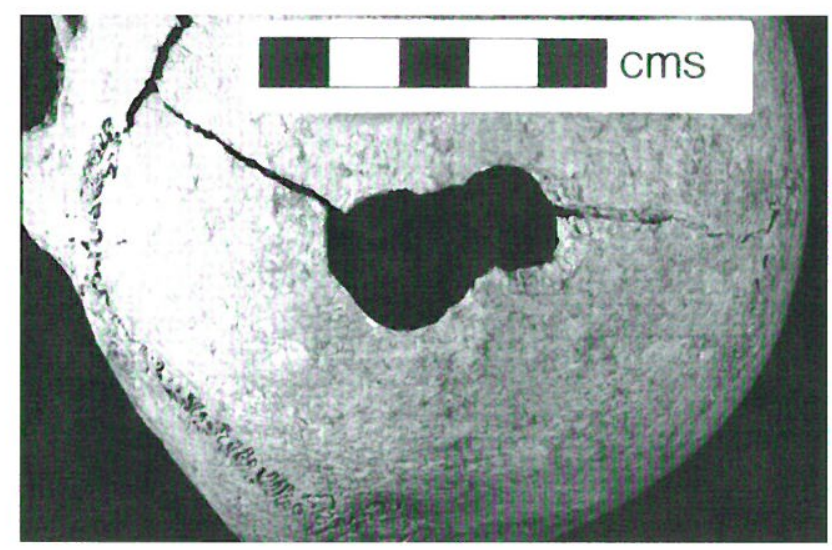

Fig. 8. 'Dorsetshire long barrow', no. 306 adult male? showing an unhealed 'keyhole' fracture to left parietal (Duckworth Collection, Cambridge).

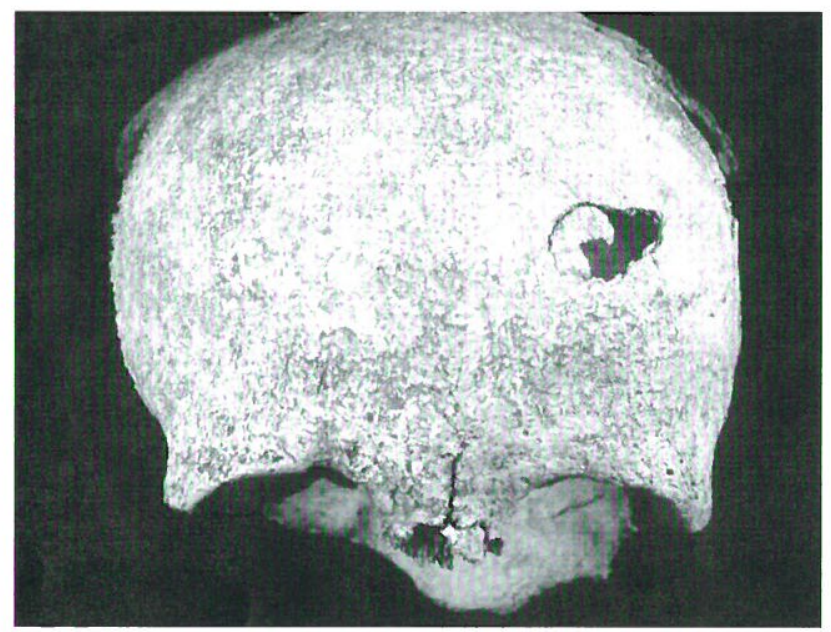

Fig. 9. Dinnington E.11.2.33/35, SU 1811 adult female with an unhealed injury to left frontal (Natural History Museum, London).

human crania are clearly river-rolled, while others are not. The majority of the dated examples fall within the earlier Neolithic, but Anglo-Saxon dates have also been obtained (on an individual showing a sword cut to the face; Turner et al. 2002, table 1). One individual, an adult male, is directly dated to the very end of the earlier Neolithic (OxA-7416: 4370 \pm 45 BP). An oval perforation at the back of the head may represent a perimortem injury, but the high energy environment of the river argues for caution in interpreting its origin. In addition, the fracture line radiating out from the perforation displays straight edges perpendicular to the bone surface that are more indicative of dry-bone breakage (Turner et al. 2002,
427; pers. observation). We place it in the medium probability category. Another individual directly dated to the Neolithic (cat. no. 1997.70.14) exhibits possible cutmarks on the rear of the left parietal. These require confirmation by examination under magnification; we do not include this example as trauma in this discussion.

In addition to the above examples, there are others for which, for one reason or another, the diagnosis is less certain. Bole's Barrow is one of a series of long barrows on Salisbury Plain from which Thurnam (1869) identified a number of 'cleft' crania. Of the four possible examples cited by him, an injury to one of the adult males is the best example, and even it is not entirely convincing. Although showing considerable interior bevelling, the injury seems disproportionate to the small amount of collateral damage shown to the surrounding bone (Fig. 12). Moreover, we have on occasion seen interior bevelling in fresh breaks on old bone, so that this alone does not always constitute an adequate criterion on which to base a diagnosis (Quatrehomme \& Iscan 1998). What is perhaps more interesting from this site is the

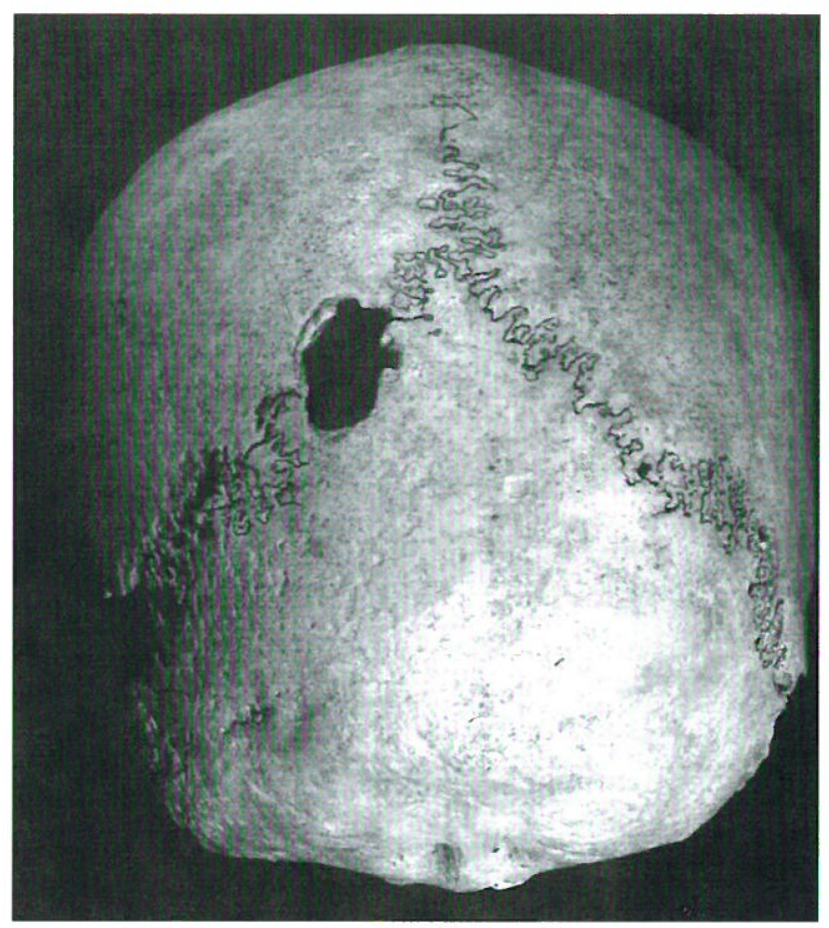

Fig. 10. Dinnington E.11.2.33-35, SU 1807 adult male with an unhealed injuiry to occipital (Natural History Museum, London). 


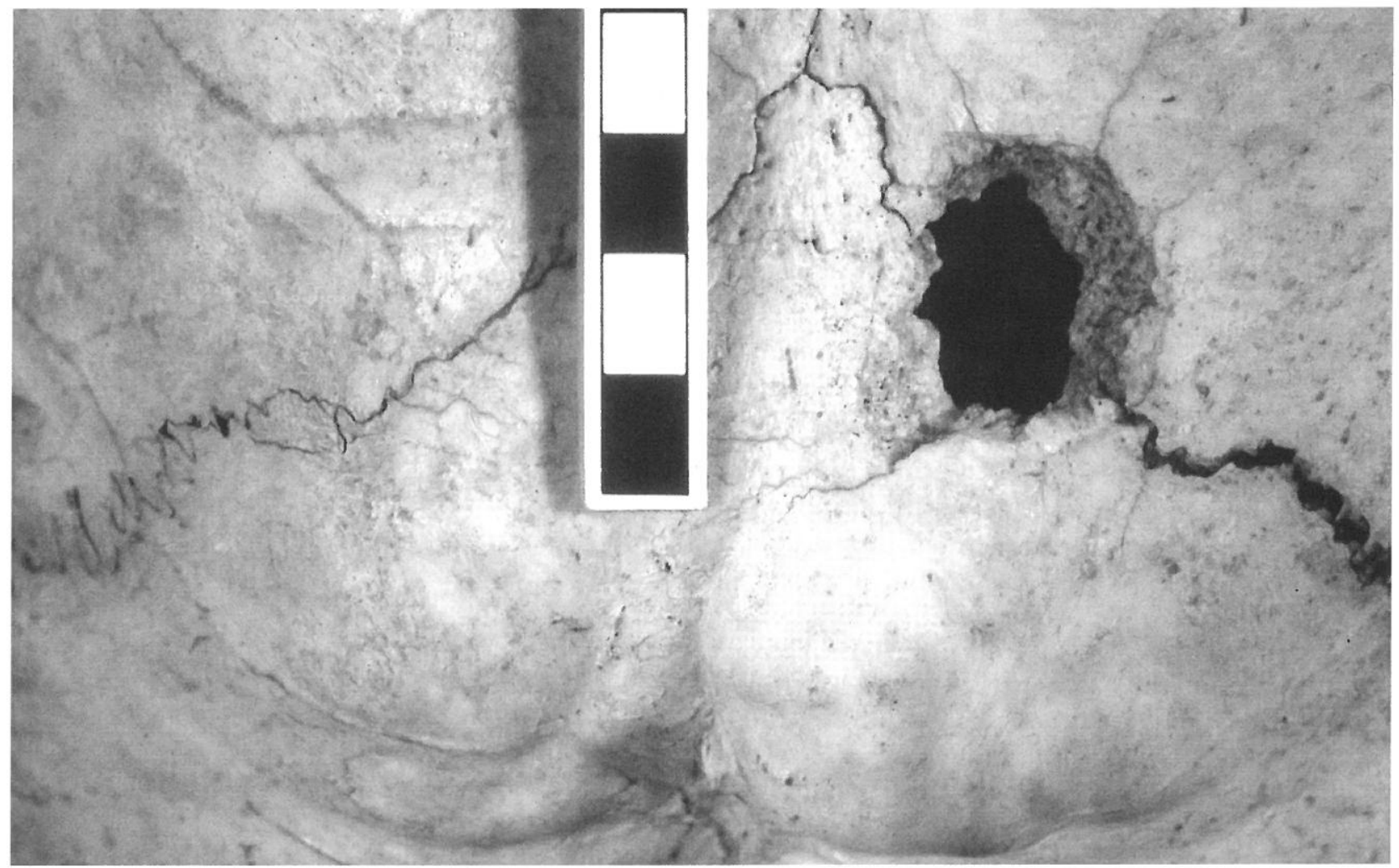

Fig. 11. Dinnington E.11.2.33-35, SU 1807 interior view of injury in Fig. 10, showing internal bevelling and small radiating fracture lines (Natural History Museum, London).

presence of clear canid scavenging marks on a number of human longbones. The implications of this are discussed below.

A cranium from Hay Wood Cave, Somerset has been reported as exhibiting an unhealed blow to its right parietal (Everton \& Everton 1972). This is a problematic example, and may reflect excavation damage. A more definitive assessment is precluded by the glue that obscures some edges. However, it does exhibit stellate fracturing surrounding the point of impact, and the edges appear patinated. It is nevertheless placed in the 'low probability' category in Table 2, pending further examination.

A number of examples of claimed injuries have proven frustratingly difficult to confirm. Foremost among these is Staines, Surrey, a causewayed enclosure near the Thames, west of London (Robertson-Mackay 1987). Two human crania were found in ditch segments, and one of these, an adult male, is reported to exhibit multiple fractures, consisting of two healing injuries to the right side of the head, four unhealed depressed fractures to the frontal, and linear fractures to the parietal (Camps et al. 1987, 10-12). While the descriptions of the injuries read convincingly, subsequent excessive plaster

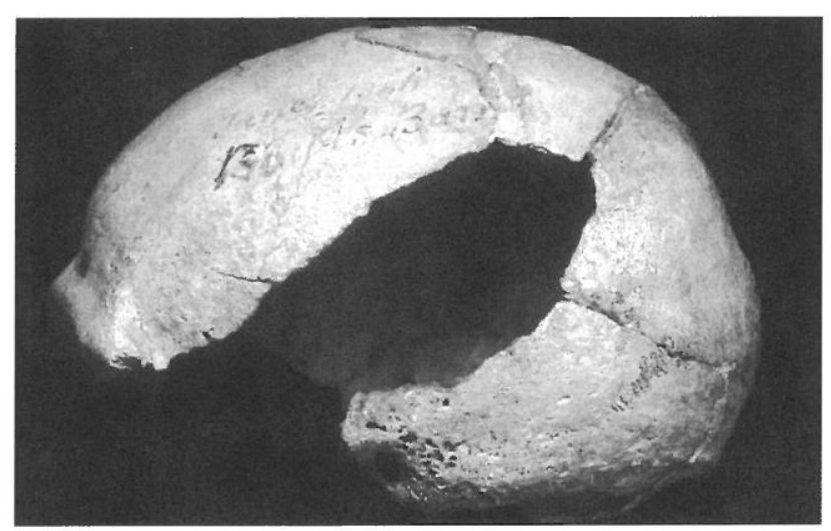

Fig. 12. Bole's Barrow C2 left lateral view of adult male with damage placed in 'low probabillity' category (Wiltshire Heritage Museum, Devizes). 
reconstruction of the specimen precludes a reassessment (Fig. 13). No photographs accompanied the original report, although both radiographs and photographs were taken $(\mathrm{H}$. Chandra, 2001, pers. comm.). Efforts are being made to locate these images.

\section{Healed examples}

A number of small depressions with well-rounded edges were observed on British Neolithic crania. Anomalies of this kind are typically identified as healed depressed fractures, and indeed there are few other known processes that can result in this type of lesion on the cranial vault. They range in size here from about $8 \mathrm{~mm}$ to $30 \mathrm{~mm}$ diameter, averaging 15 by $10 \mathrm{~mm}$ (Table 2). In some examples the edges of the depressions are slightly raised (Fig. 14) - this is part of the healing process. We are confident that the majority of these represent traumatic injury rather than any other process. Most likely result from interpersonal violence, although of course some may reflect accidents. Some are very slight depressions, and none shows clear involvement of the inner table of the cranium; these would represent relatively mild blows

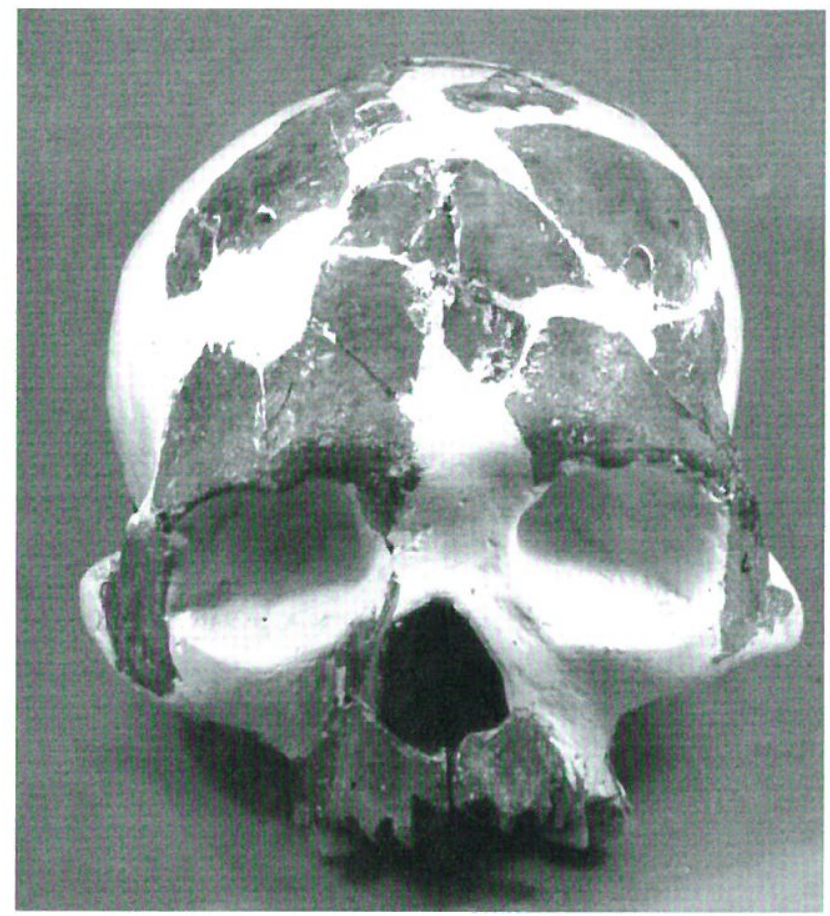

Fig. 13. Staines 'skull B' frontal view; it is not possible to confirm claimed injuries to this specimen due to excessive plaster reconstruction (British Museum, London).

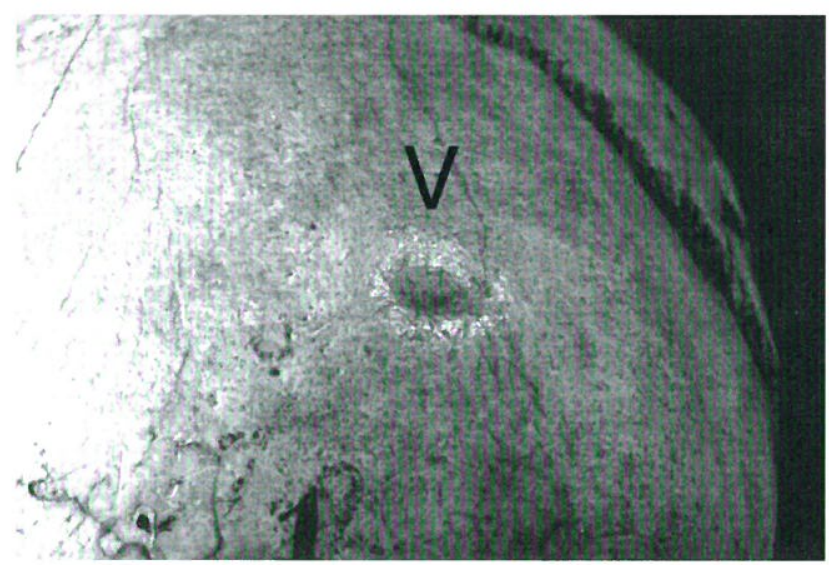

Fig. 14. Norton Bavant Eu.1.5.92 adult male with a healed depressed fracture to left frontal (Duckworth Collection,

Cambridge). ' $\mathrm{V}$ ' points to location of injury.

to the head. As with the cases of unhealed trauma discussed above, they are found on both males and females. The former include examples from the sites of Norton Bavant, West Tump, Rodmarton, Fussell's Lodge, and Dinnington. An adult male from Hambledon Hill exhibits a healed oval depression (McKinley forthcoming). Very shallow depressed areas on two male crania from Tinkinswood 'A' and 'B', Glamorgan, may also be of traumatic origin. The depression on the left parietal of Tinkinswood ' $A$ ' is found near, but not coinciding with, a lytic lesion suggesting an infection (Fig. 15). Its localised nature and the depression that forms its centre suggests that this could also be of traumatic origin, and in fact a very similar lesion is seen surrounding an embedded obsidian projectile point tip in a cranium from prehistoric California (Jurmain $\&$ Bellifemine 1997, fig. 3).

Fussell's Lodge, Wiltshire, is an especially interesting case, as there are three well-healed depressions along the top of the right parietal (Fig. 16). Another male cranium from the site exhibits what Brothwell and Blake $(1966,59)$ identified as either a healed trepanation or a healed depressed fracture, though favouring the former interpretation. No cut, drill, or scrape marks are visible, although the bone remodelling associated with the healing process might be expected to have obliterated these (Fig. 17). Brothwell and Blake $(1966,60)$ also discuss a second possible healed trepanation or depressed fracture on a charred parietal fragment; this specimen could not be located for re-examination. Unfortunately both specimens are incomplete, and so it is difficult to be 


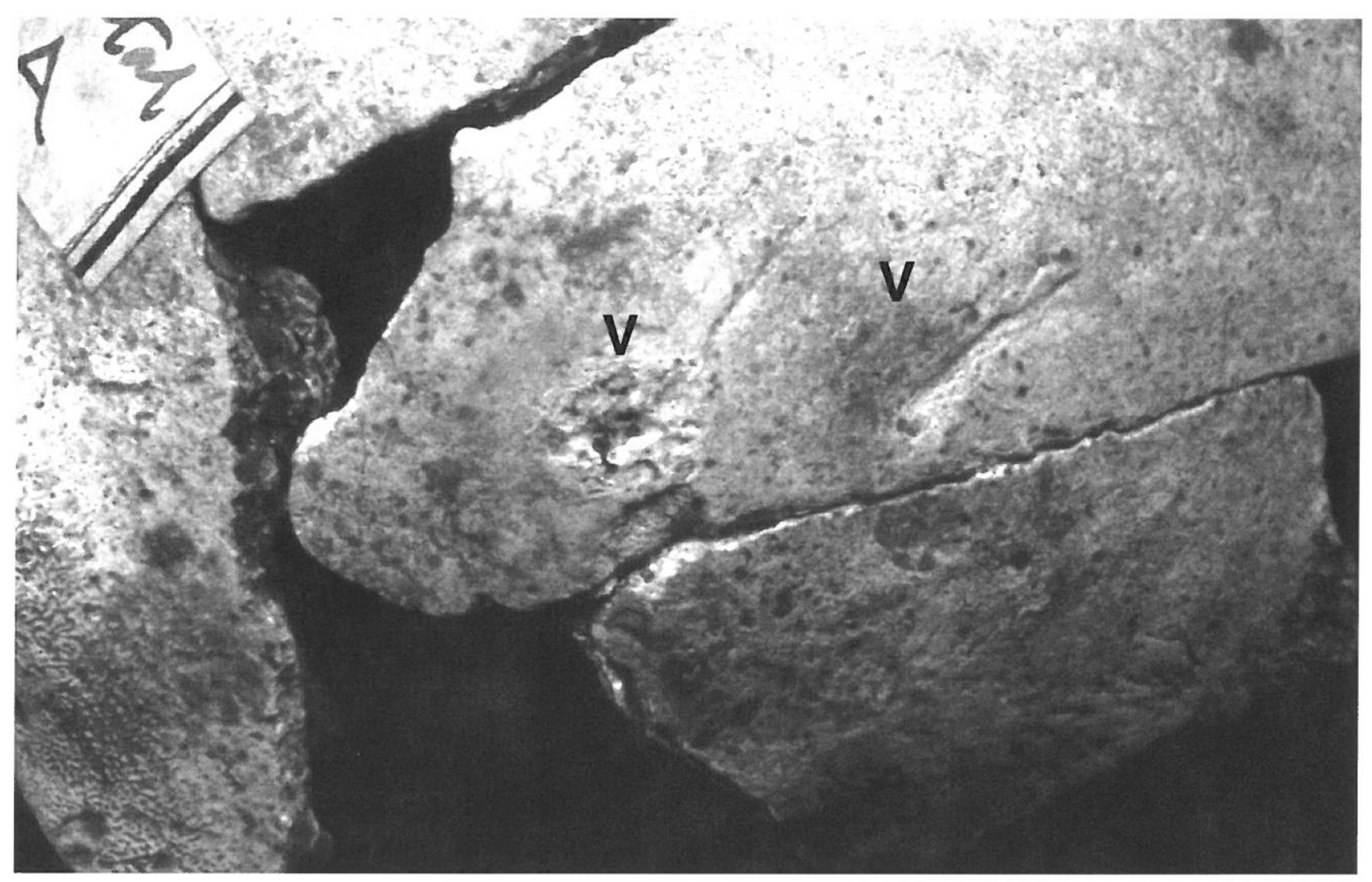

Fig. 15. Tinkinswood A with small healed fracture and adjacent lesion suggestive of localised infection, possibly from an arrow wound (National Museums and Galleries of Wales, Cardiff). 'V' points to locations of injuries.

certain one way or the other; Parker et al. (1986) accept both as trepanations, but we would suggest that they are equally likely to represent depressed fractures (see Bennike (2003) for a re-interpretation of claimed cases of trepanation in prehistoric Denmark as often more likely to represent healed depressed fractures). It can be noted that in a number of cases in the European Neolithic and elsewhere, trepanations have been shown to be performed on parts of the cranium exhibiting signs of fracturing, so that this may have been in part a surgical procedure for treating a severe blow to the head (Bennike 1985; Chege et al. 1996; Ortner \& Putschar 1985, 96; Verano 2003; Martin 2003).

An adult male from Preston Docks (cat. no. 1977.70.8) shows a well-healed depressed fracture to the back of the cranium (Turner et al. 2002; pers. observation). This is not included in Table 2 due to uncertainty concerning its date.
The skeletal material from Winterbourne Monkton, Littleton Drew, and Lyneham, all in Wiltshire, each include an adult female cranium with a well-healed depressed fracture (Fig. 18). Aside from the probable female with unhealed cranial injuries discussed above, a second adult female from Coldrum shows a small, well-healed depressed fracture near the midline of the frontal. A classic example of a healed depressed fracture is seen on the rear left parietal of an adult female from Dinnington (Fig. 19). In addition, both Penywyrlod and Hambledon Hill provide probable healed depressed fractures on individuals of unknown sex. As mentioned above, Penywyrlod is also of interest for an embedded projectile point recently found embedded in a rib, in this case showing no signs of healing (Wysocki \& Whittle 2000, fig. 5). Not yet examined by the authors is a reported double trepanation that could also represent two well-healed depressed fractures, on an adult cranial fragment of 


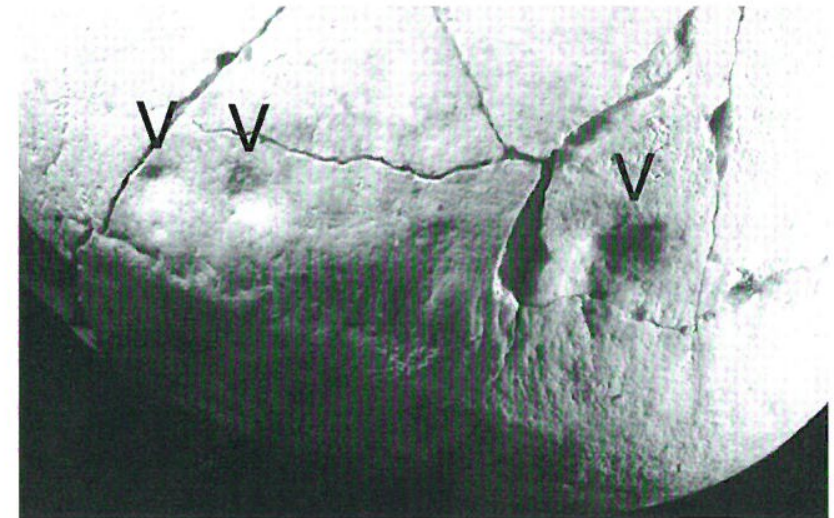

Fig. 16. Fussell's Lodge 1960.20.5.7, SK 3318 adult male with three healed depressed fractures to the top of the cranium (Natural History Museum, London). 'V' points to locations of injuries.

unknown sex from the Millbarrow chambered tomb, only some $300 \mathrm{~m}$ from Winterbourne Monkton (Brothwell 2003; Brothwell in Whittle 1994).

Whatever the status of the damage to the Hay Wood cranium, discussed above, a mandible from a different individual at the site does show a definite well-healed fracture. This is one of the few examples we have found of an injury to the front of the face (not strictly 'cranial' trauma, and so excluded from the summaries presented below). The incidence of facial injury may be greater than suggested by the sparse evidence, as the thin facial bones are very frequently heavily damaged or missing entirely in many of the collections examined. It is worth noting that close quarters interpersonal violence, at least in modern Western society, is often directed at the face (Walker 1997).

Hartlepool Bay, Durham, presents another frustrating case. An isolated male skeleton found in foreshore peats was directly dated to the earlier Neolithic (Hv. 5220: 4680 \pm 60 BP). Two well-healed depressed fractures to the frontal of this individual, together with a healed rib fracture, were described by Rosemary Powers (in Tooley 1978), then of the Natural History Museum, London. Unfortunately, when the material was re-examined the crucial frontal bone could not be located, although the rib fracture was confirmed. The available photograph is not of sufficient quality to permit confirmation of the cranial injuries. However, given the experience of the analyst, and the description and accompanying drawings, this example is provisionally accepted here.

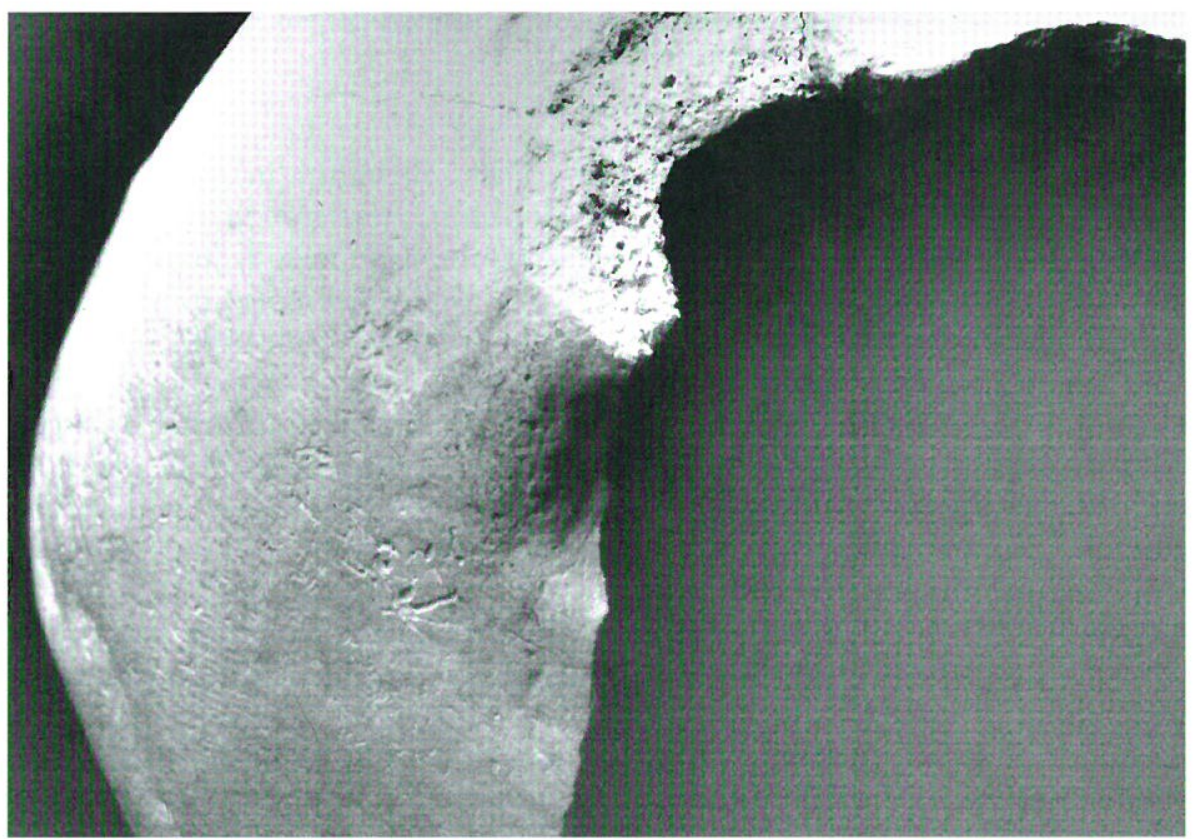

Fig. 17. Fussell's Lodge adult male 1960.20.5.11, SK 3322 with healed depressed fracture or trepanation in middle of field (Natural History Museum, London). 


\section{R. Schulting and M. Wysocki EVIDENCE FOR CRANIAL TRAUMA IN THE BRITISH NEOLITHIC}

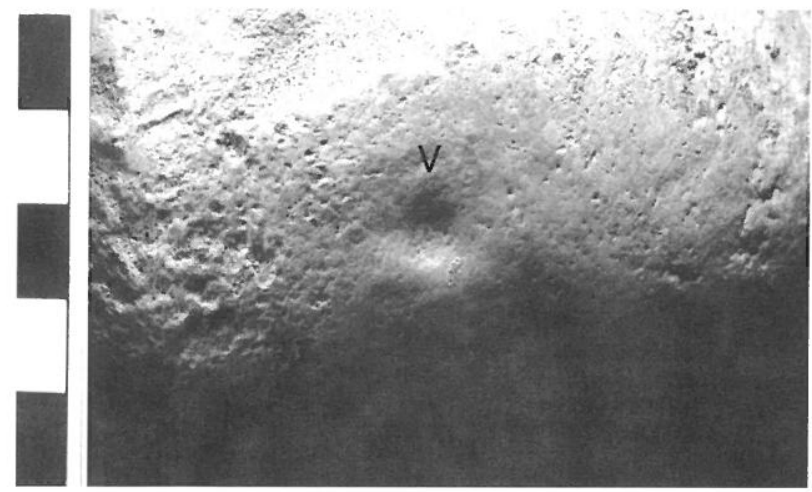

Fig. 18. Lyneham 1952.2.20/2, SK 3304 adult female? with healed depressed facture to left parietal (Natural History Museum, London). 'V' points to location of injury.

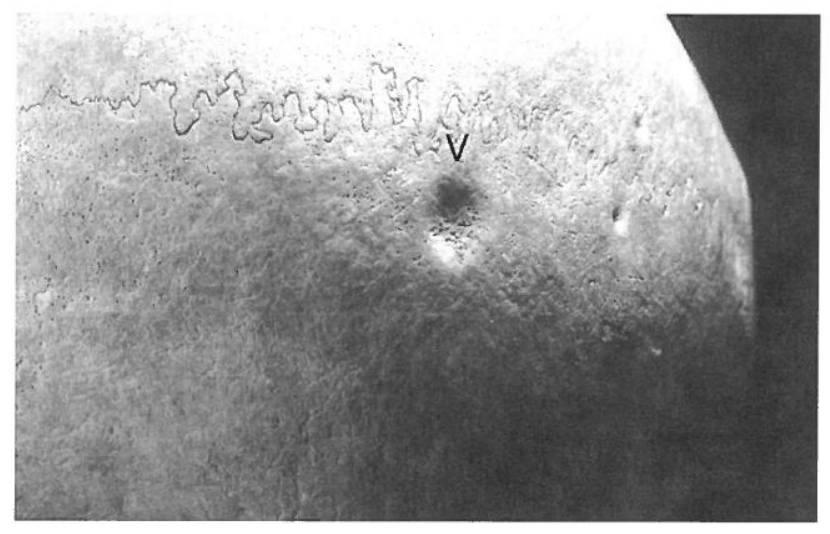

Fig. 19. Dinnington E.11.2.33-35, SU 1817 adult female with healed depressed fracture to rear of left parietal (Natural History Museum, London). 'V' points to location of injury.

\section{DISCUSSION}

Assessing the damage: a summary of unbealed and healed injuries and a population perspective

Including Staines, there are 10 individuals with unhealed injuries from seven sites, with Belas Knap, Coldrum, and Dinnington each having two cases. One of the Coldrum crania exhibits two injuries, while the Staines cranium reportedly had four unhealed injuries to the frontal and another possible injury to the parietal. It is particularly unfortunate that more information is not available for Staines, since this seems to represent a clear example of 'overkill' that is of some interest in discussing the possible context for violence in this case. The other examples are each represented by a single injury.
Including Staines, Hambledon Hill, Hartlepool Bay, Millbarrow, and the missing second trepanation/ depressed fracture from Fussell's Lodge, there are 21 individuals from 15 sites exhibiting a total of 26 healed injuries (excluding these sites gives 14 individuals exhibiting 17 injuries). In the majority of cases there is only one injury per individual. Two healing or healed injuries are reported on adult males from Staines, Hartlepool, and Millbarrow, and have been observed on a probable adult female from Winterbourne Monkton, while an adult male from Fussell's Lodge has a total of three well-healed depressions, in a row on top of the cranium. While perhaps one injury on the top of the head could be the result of an accident, it is difficult to conceive how three injuries could be caused in this way. All appear to be in a similar condition, so that it is not possible to say whether they occurred at the same time, or on two or three separate occasions.

Of the ten individuals with unhealed injuries in the high/medium probability categories, those from Staines, Belas Knap, and Preston have already been noted in the literature, although those from Belas Knap have received no attention since their publication by Crawford (1925). Of the 15 sites with examples of healed cranial injuries, Hambledon Hill, Staines, Hartlepool Bay, the two possible trepanations from Fussell's Lodge, and from Millbarrow have been previously reported in the literature. Many of the new examples presented here are from older excavations, with inadequate initial examination of the human skeletal material. In addition, a number are quite small injuries, or are on partial crania, and would be easily missed in a cursory examination. Thus we have here confirmed (or rejected) a number of cases of cranial trauma previously presented in the literature, as well as having identified a considerable number of new examples.

To achieve the goals outlined in the beginning of this paper, it is crucial to place the cranial evidence for interpersonal violence into a broader population perspective. This is not as straightforward a calculation as it might at first appear. Some of the examples examined remain problematic, in no small part due to the partial and fragmentary nature of the majority of British Neolithic skeletal remains. The presence of ten frontal bones indicates ten individuals, but does not provide the same probability of scoring trauma as would ten complete crania. The practice of reconstruction also frequently obscures the necessary 
evidence, the Staines cranium providing the most extreme - but far from the only - example.

With all of these caveats in mind, it is possible to at least suggest some preliminary figures. As noted above, we have examined some 350 composite crania in sufficient condition for a reasonable assessment to be made. The majority of examples were personally examined by at least one of the authors, and most were examined by both. The exceptions to this are Staines, Hartlepool Bay, and the healed trepanation/depressed fractures from Fussell's Lodge and Millbarrow, and Hambledon Hill. For the first three sites, the collections were examined but the relevant evidence could not be re-assessed, either because the element in question could not be found or because the relevant area was not observable. In the case of Millbarrow and Hambledon Hill, the collections have not yet been examined. These examples are nevertheless included here for the sake of completeness, because of the quality of the descriptions and the experience of the researchers involved. Evidence for trauma on 31 of the $350 \mathrm{crania}$ gives an overall incidence of $8.9 \%$, with $2.9 \%$ unhealed (ie, themselves lethal, or part of a suite of lethal injuries) and $6.0 \%$ healed. Twenty-one of the 31 examples $(70 \%)$ are in the high probability category. Assuming some examples in the medium probability category have been misdiagnosed (eg, the Ebberston and Preston Docks examples border on the low probability category), and that some of those injuries in the high/medium probability categories are the result of accident rather than conflict, a final conservative estimate of $5-7 \%$ cranial trauma seems warranted. Even such a seemingly low incidence translates as one in 20 individuals - or at least one or two individuals per small local community - being involved in either lethal or non-lethal interpersonal conflicts resulting in cranial trauma during their lifetime. Thus, most people would be expected to have experience of someone known to them, involved in an incident of interpersonal violence of sufficient severity to permanently mark the cranium.

It should be emphasised that this figure refers only to the incidence of cranial trauma, and not to the overall incidence of interpersonal violence in the population, which would need to consider both cranial and postcranial evidence. Nor does the figure reflect the incidence of lethal trauma, but rather of cases of probable interpersonal violence, whether lethal or not, affecting the cranium. In fact, there are over twice as many cases of healed compared with unhealed examples of trauma. At present, the incidence of lethal cranial trauma may be estimated as approximately $2 \%$ of the British Neolithic population. Again, this may be under-represented by difficulties of diagnosis, preservational bias, and the need to be conservative in accepting cases as showing either high or at least medium probability (see also Jurmain \& Bellifemine 1997, 49). Thus, for example, the five specimens in the excluded low probability category in Table 2 are all unhealed fractures.

In a world-wide context, a mortality rate of $2 \%$ is rather low (contrary to the impression we gave earlier in Schulting and Wysocki $(2002,5)$, where it was described as neither remarkably high nor remarkably low). Keeley (1996, table 6.2) provides estimates for violent deaths in small-scale societies ranging from $8 \%$ to $33 \%$, while Gat (1999) suggests an average figure of $15 \%$ violent deaths. However, a comparable figure for the British Neolithic would have to include all violent deaths, not just those resulting from cranial trauma. At the moment it is not possible to provide such a figure. The bow would likely be the weapon of choice in the British Neolithic, and, as noted earlier, there are many difficulties in identifying projectile point trauma, particularly when dealing with the partial and scattered remains that are typical of British mortuary contexts. Were associated leaf-shaped arrowheads to be interpreted as cause of death rather than as grave offerings, the figure for Britain would begin to approach those cited by Keeley and Gat. Estimates of rates of cranial injury on prehistoric skeletal materials vary widely worldwide; across much of North America figure of $2-5 \%$ are common, though they can be considerably higher, such as in California (Jurmain 1999, 197-8). Closer to Britain, the incidence of cranial lesions reported for Neolithic Denmark is as high as c. $10 \%$ (Bennike 1985, table 15). Although not yet quantifiable, other postcranial injuries have been noted on British Neolithic material, in the form of so-called 'parry fractures' to the midshaft of the ulna (usually left) (eg, Fussell's Lodge, Lanhill, and Wayland's Smithy), and rib fractures (eg, Hartlepool, Hazleton North) (Bothwell 1961; Brothwell \& Blake 1966; Brothwell \& Cullen 1991; Rogers 1990; Wysocki n.d.). While the interpretation of breakages to the ulna as parry fractures rather than accident is recognised as problematic (eg, M. Smith 1996), they, along with fractures to the ribs and hand, are still often seen as indicative of interpersonal 


\section{R. Schulting and M. Wysocki EVIDENCE FOR CRANIAL TRAUMA IN THE BRITISH NEOLITHIC}

violence (Lovell 1997). The aforementioned examples are all healed; it would be very difficult to identify unhealed forearm and rib fractures in the fragmentary material available.

In light of the rather small sample size, the attempt to assess correlations between age and sex, and location and condition (healed vs unhealed) of the injuries is fraught with difficulties. Twenty-nine of the 31 examples discussed here are on adults. The two exceptions are an unhealed injury to a probable adolescent from Belas Knap, and a healed depressed fracture on an older adolescent or young adult from Hambledon Hill (McKinley forthcoming). A child from the Whitwell long cairn in Derbyshire exhibits a possible trepanation, but more likely reflects postdepositional damage (Witkin \& Chamberlain in prep.) and is placed in the low probability category here. But then there are relatively few subadults in the sample examined thus far, and they tend to be even more fragmentary. It is also important to recognise that well-healed depressed fractures on adults could be the result of trauma occurring many years prior to death, possibly during childhood or adolescence. With regards to sex, an assessment based largely on a literature survey indicated that the majority of examples of interpersonal violence of varying kinds occurred on males, with a far smaller number of examples on females (Schulting 1998, appendix 5.3). Our re-assessment of the skeletal evidence to date indicates a very different pattern at least for cranial trauma, with approximately equal representation of males and females. Given that there are more males than females in the overall sample, the incidence of trauma is actually somewhat higher for females $(10.7 \%$ vs $12.9 \%)$, although not significantly so (Table 3). There are no significant correlations between sex and the location or condition of cranial injuries, a point to which we return below.

Location on the cranium is one means of assessing the possible origins of the injuries. The 26 healed fractures discussed here are distributed fairly randomly around the cranium, with very nearly equal numbers to the left and right sides (Fig. 20). This lack of side preference would be expected with a projectile weapon such as a sling, or a thrown stone. By contrast, there does seem to be more in the way of patterning in the locations of unhealed injuries. Seven individuals exhibit unhealed injuries on the left side of the head compared with two on the right and two on the rear. Two of the individuals with injuries to the left
TABle 3. SUMmARY STATISTICS FOR INJURIES IN HIGH/MEDIUM CATEGORIES

\begin{tabular}{lccc}
\hline Low vs. condition & (injuries counted seperately) \\
& healed & unhealed & Totals \\
L side & 11 & 10 & 21 \\
R side & 12 & 2 & 14 \\
rear & 3 & 2 & 5 \\
Totals & 26 & 14 & 40
\end{tabular}

Location vs. condition (multiple injuries to the same location counted as one occurrence)

$\begin{array}{lcccc} & \text { healed } & \text { unhealed } & \text { Totals } \\ \text { L side } & 11 & 7 & & 18 \\ \text { R side } & 8 & 2 & & 10 \\ \text { rear } & 2 & 2 & & 4 \\ \text { Totals } & 21 & 11 & & 32 \\ & & & & \\ \text { Location vs. sex } & & & & \\ & \text { male } & \text { female } & \text { indet. } & \text { Totals } \\ \text { L side } & 9 & 5 & 4 & 18 \\ \text { R side } & 4 & 3 & 2 & 9 \\ \text { rear } & 3 & 1 & & 4 \\ \text { Totals } & 16 & 9 & 6 & 31\end{array}$

Sex vs. condition

$\begin{array}{lccc} & \text { bealed } & \text { unhealed } & \text { Totals } \\ \text { male } & 11 & 5 & 16 \\ \text { female } & 5 & 4 & 9 \\ \text { indet. } & 5 & 1 & 6 \\ \text { Totals } & 21 & 10 & 31\end{array}$

\begin{tabular}{lrrrr} 
& \multicolumn{1}{c}{$n$} & \multicolumn{1}{c}{$\%$} & \multicolumn{2}{c}{ average $(\mathrm{mm})$} \\
& & & length & width \\
crania examined & 350 & $100.00 \%$ & & \\
unhealed & 10 & $2.86 \%$ & 24.7 & 12.9 \\
healed & 21 & $6.00 \%$ & 14.5 & 10.3 \\
total & 31 & $8.86 \%$ & & \\
male $(150)$ & 16 & $10.67 \%$ & & \\
female $(70)$ & 9 & $12.86 \%$ & & \\
& & &
\end{tabular}

side of the head show multiple blows, two in the case of Coldrum and a reported three in the problematic case of Staines, with a further injury to the right side. Thus, in terms of locations of number injuries, there are ten to the left side, compared with two each to the right side and to the rear. (It should be noted that 'right' and 'left' sides are used here in a very strict sense - a more nuanced analysis might employ a more precise definition of location, eg, injuries to the top of the head, falling near the midline, should probably be treated separately; given the small sample size we have not pursued this approach here.) A predominance of injuries to the left side of the head might be expected with a right-handed assailant in a face-to-face confrontation. The probability of the observed left/right distribution of unhealed injuries occurring randomly is low (binomial $p=0.0193$ ), as is the 
Left lateral
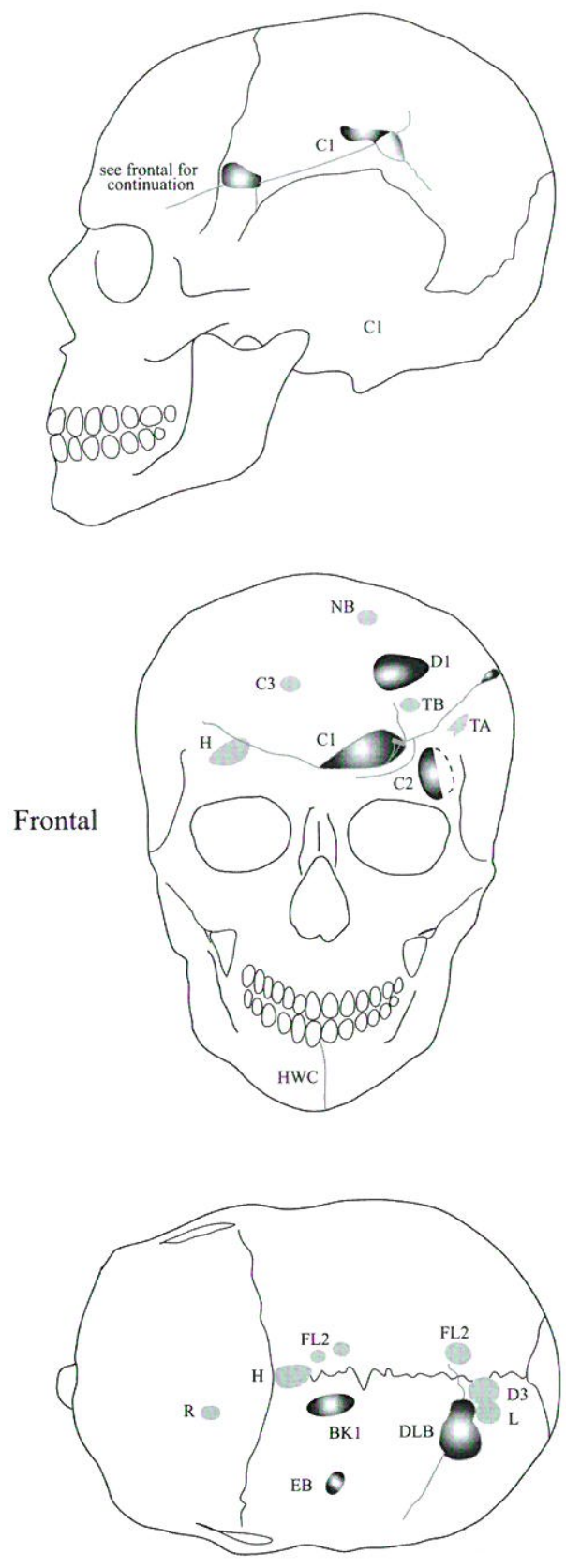

Superior
Right lateral
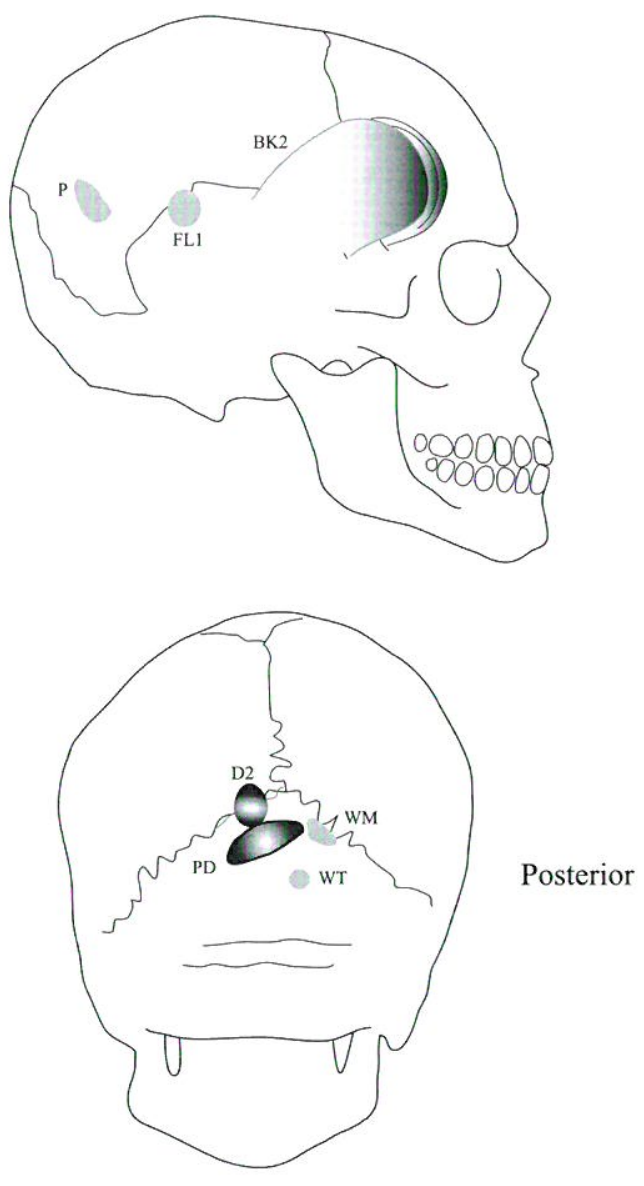

BB - Bole's Barrow C2

BK1 - Belas Knap DII

BK2 - Belas Knap D4

C1 - Coldrum Eu. 1.5.120

$\mathrm{C} 2$ - Coldrum ' 8 '

C3 - Coldrum Eu.1.5.125

D1 - Dinnington E.11.2.33-35, SU 1811

D2 - Dinnington E.11.2.33-35, SU 1807

D3 - Dinnington E.11.2.33-35, SU 1817

DLB - 'Dorsetshire' long barrow

H - Hartlepool

HWC - Hay Wood Cave

EB - Ebberston E.11.2.4, SU 1795

FL1 - Fussell's Lodge Sk 3322

FL2 - Fussell's Lodge Sk 3318

L - Lynham 1952.2.20/2, SK 3304

NB - Norton Bavant Eu.1.5.92

P - Penywyrlod

PD - Preston Docks 1997.70.7

R - Rodmarton 4.02, SK 13

TA - Tinkinswood A

TB - Tinkinswood B

WT - West Tump E.11.2.44/45, SU 1826b

WT - West Tump

WM - Winterbourne Monkton Eu.1.5.45

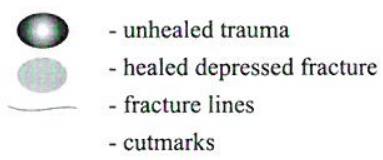

Fig. 20. Composite views showing locations of healed and unhealed injuries in high and medium probability categories. 


\section{R. Schulting and M. Wysocki EVIDENCE FOR CRANIAL TRAUMA IN THE BRITISH NEOLITHIC}

probability of the observed left/right distribution of healed and unhealed injuries (Fisher's $p=0.0385$ ). There is some indication, then, of patterning in the locations of unhealed and healed injuries. This in turn could reflect different contexts for lethal and nonlethal interpersonal violence, as discussed further below. The number of examples are too few at this stage to do more than submit this as a possibility for further consideration. It is also worth noting that four of the five excluded unhealed breakages in the low probability category are to the left side of the head (the sixth being the possible trepanation on a child from Whitwell long cairn).

\section{Weapons}

The absence of a class of obvious weapons is no doubt one factor that has tended to downplay the importance of interpersonal violence in the British Neolithic. But then the apparent lack of more formal offensive and defensive equipment, such as is found in the Bronze Age, may have more to do with the status of the warrior and gender identities than with the actual incidence of violence (Treherne 1995). And of course this perception depends on one's views of the main function of the bow (Green 1980; Mercer 1999), and of the polished stone axe (Figs 21 a-e). Antler 'picks' could also be effective weapons as well as digging tools. Indeed, the division between weapons and tools is often an artificial one (Chapman 1999; Whittle 1996, 277). That antlers were used as digging tools is incontrovertible given their common presence in the ditches of causewayed enclosures and mortuary monuments, and in flint mines. Yet it is noteworthy how similar some British Neolithic antler 'picks' are to those found in Mesolithic graves at Téviec and Hoëdic in Brittany (Péquart \& Péquart 1954, pl. 7), where it is harder to argue that they functioned as analogous digging tools. More difficult to address is the crucial question of other organic artefacts mainly wood and leather - that do not survive except under the most exceptional circumstances. Wooden weapons, and in particular clubs, are very common worldwide, and are very effective in close-quarters fighting. Defensive gear, such as shields and clothing, is often made of wood and hide, and may be more effective than more costly equivalents made of metal (Coles 1977). Organic evidence from Britain is limited, but does exist (Fig. 21). Together with a number of well-known and powerful Early Neolithic bows, an example of a complete wooden spear has been found at the Sweet Track, Somerset, along with a wooden club or mattock (Coles et al. 1973, 281; for bows, see also Clark 1963; Sheridan 1996). Two more convincing examples of wooden clubs were found at the earlier Neolithic site of Ehenside Tarn in Cumbria in the 1870s, together with what may be a throwing stick (Darbishire 1874; Piggott 1954, 296-7, fig. 47). Another wooden club fragment from the site exhibited a finely incised lattice pattern (Fig. 21g). Most recently, a complete and substantial wooden club has been found from the foreshore of the Thames at Chelsea, and has been directly dated to $4660 \pm 50 \mathrm{BP}$ (Beta-117088) (Webber \& Ganiaris 2004) (Fig. 21j). From a later period, an oak object in a Beaker grave at Cairnpapple has been interpreted as a probable club (Piggott 1948).

The observed British Neolithic healed injuries predominantly take the form of small round or oval depressions, while the shape of the unhealed injuries is highly variable. Most of the unhealed injuries seem to be the result of blunt force trauma, of the kind that would be produced by a club of stone, antler, or dense wood. The Belas Knap adolescent presents a classic example of a massive blunt force trauma caused by such a club. The 'keyhole wounds' seen on the Dorsetshire cranium and the rear of the Coldrum cranium may have been delivered by either a blunt or pointed implement striking at a shallow angle, possibly against a prone individual (Figs $5 \& 8$ ). The unhealed injury to the frontal of the Dinnington cranium has a distinctive shape (Fig. 9; see also Belas Knap, Fig. 4), although it is difficult to relate it to any recognised standard Neolithic implement type (perhaps the corner of a polished stone axe?). The unhealed injury to the frontal of the Coldrum cranium is perhaps closest to the lozenge shape that would be expected from a stone axe. Good examples of this kind of injury are seen on a number of crania at the Neolithic site of Talheim in southern Germany (Wahl \& König 1987).

Small healed depressed fractures of the kind seen on a number of British crania are found in many parts of the world, and can be caused by various implements. They are reminiscent of sling-stone injuries seen where slings were known to have been used in warfare in prehistory, such as Peru and the Canary Islands (Ortner \& Putschar 1985; Verano 1997). However, there is no convincing evidence for the use of the sling in the British Neolithic. Nevertheless, a few examples of possible sling stones have been put forward, such as 


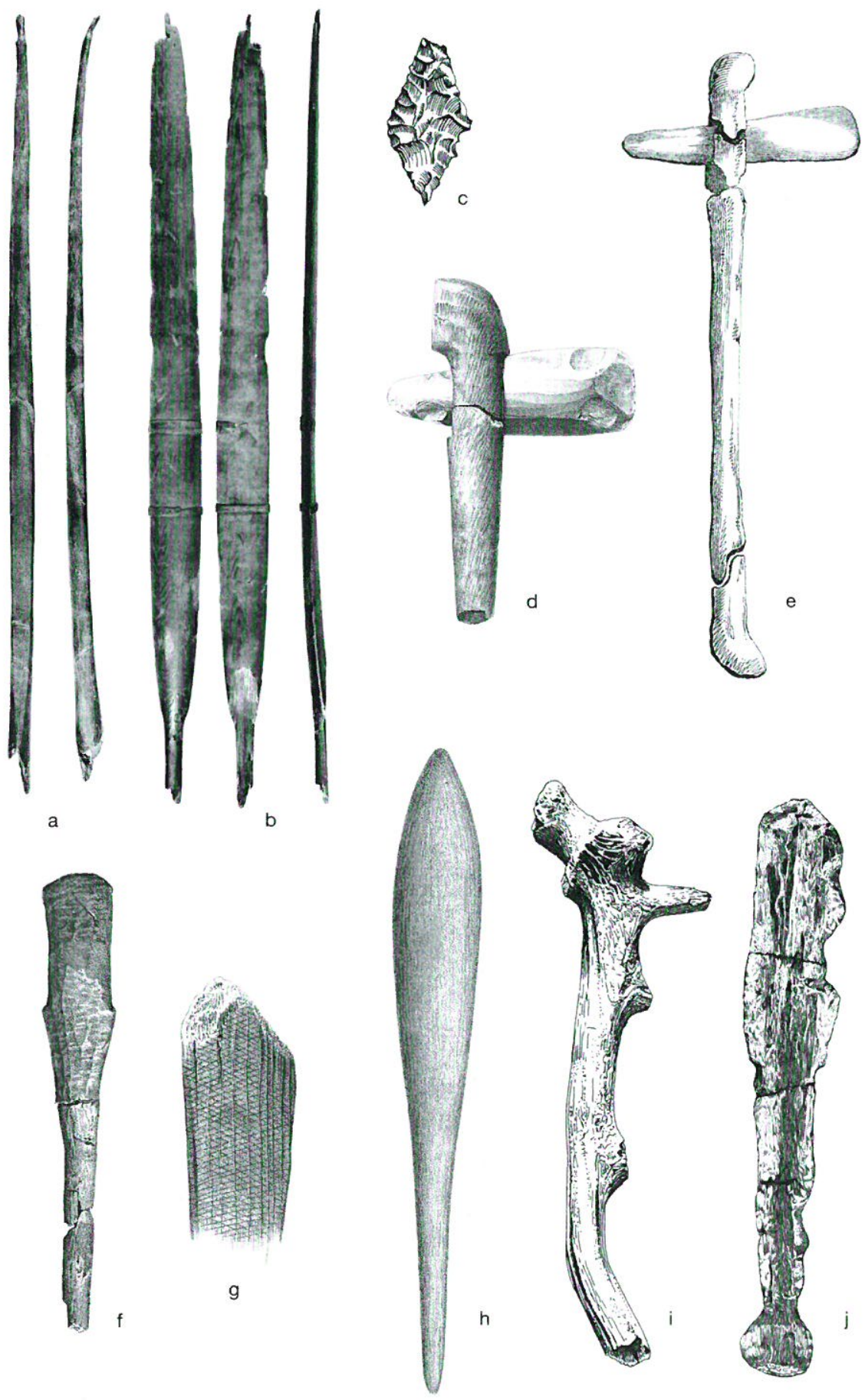

Fig. 21. A selection of possible earlier Neolithic weapons (not to scale). Neolithic bows from (a) Ashcott and (b) Meare, Somerset (courtesy of Cambridge University Museum of Archaeology \& Anthropology); (c) leaf-shaped flint arrowhead with broken tip found between ribs of adult male skeleton at Wor Barrow (Pitt-Rivers 1898, pl. 260, fig. 5); (e) hafted axe from Solway Moss (from Musgrave 1857); (d, f-h) hafted axe and wooden clubs from Ehenside Tarn, Cumbria (from Darbishire 1874); (i) antler pick from Stonehenge (after Cleal et al. 1995, fig. 233); (j) wooden club from the Thames foreshore at Chelsea (after Webber \& Ganiaris 2004, fig. 14.1). Figs 21c, i and $\mathrm{j}$ were drawn by Libby Mulqueeny. 


\section{R. Schulting and M. Wysocki EVIDENCE FOR CRANIAL TRAUMA IN THE BRITISH NEOLITHIC}

a number of small rounded stones found at the chambered tomb of Tinkinswood (Ward 1915). Bird (1865) reports an injury to the left side of a skull from a Wiltshire round barrow that he suggests may have been caused by sling stone, although this must be treated with great caution. The identification of sling stones, which after all would require little or no modification, could be problematic if they were not recognised as a possibility beforehand (Vutiropulos 1991). That being said, it seems unlikely that large numbers of sling stones have been missed, particularly at sites such as Hambledon Hill (Mercer 1988; 1999) and Crickley Hill (Dixon 1988), where the excavators were very much aware that they were dealing with defences that had been subjected to large-scale attack, and where long-distance weaponry such as slings would be expected to be employed were they in general use. Certainly many hundreds of arrowheads were found at Crickley Hill, clustering at the entrance.

In any case, similar cranial injuries could also be caused by instruments terminating in a blunt point, such as antler tines, or hardwood weapons or tools. An adult female skull from ancient Peru exhibits a series of unhealed depressed fractures which, had the individual survived and the injuries healed, would present a very similar appearance to those found singly on British Neolithic crania (Fig. 22). In this case the injury is thought to have been caused by a wooden or stone star-headed mace, often seen depicted in Moche iconography. Glancing blows from arrows or hand-thrown wooden-tipped spears could also have

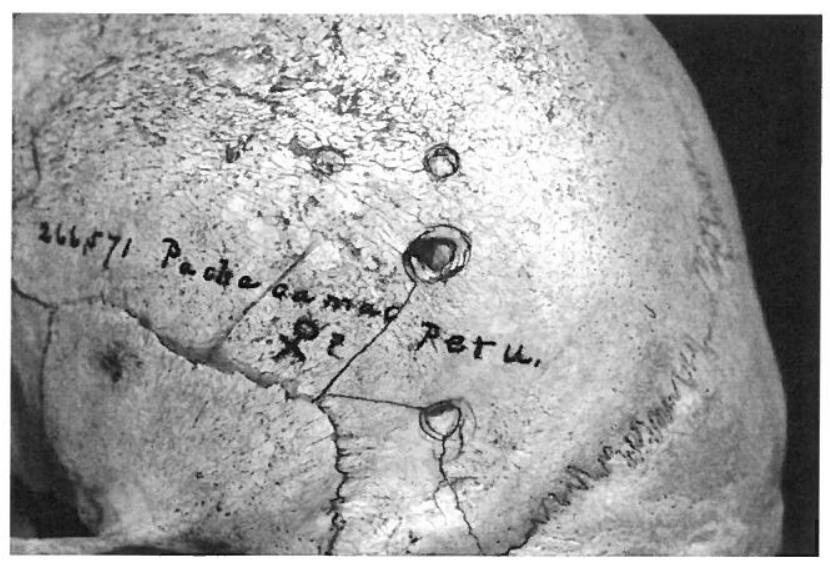

Fig. 22. Cranium from prehistoric site of Pachacamac in Peru showing small unhealed depressed fractures (from Ortner \& Putschar 1985, fig. 69, used with permission of D. Ortner). caused some of the healed injuries seen on British Neolithic crania. Hand-thrown stones, an effective weapon used even in Roman times (Elton 1996, 108), would present comparable patterning to that seen in sling-stone injuries. Standen and Arriaza (2000) surmise that hand held or hand thrown stones could have been responsible for the high incidence $(24.6 \%)$ of healed cranial fractures in a prehistoric population from northern Chile.

\section{Contexts for interpersonal violence}

The great majority of the examples of cranial trauma presented here derive from mortuary monuments. This clearly presents a bias, albeit one made necessary by the difficulty of attributing individuals found in other contexts to the Neolithic period. It is only possible to discuss the exceptions when they have been directly dated (eg, Preston Docks) or when they are part of a seemingly single-period group of remains dating to the Neolithic (eg, Hay Wood Cave). A number of additional examples of blunt-force cranial trauma were in fact identified in the course of the present project (eg, Preston Docks), but with no idea of their date they could not be included. Clearly a programme of targeted AMS dating is called for.

As has long been recognised, Neolithic mortuary monuments must contain only a small fraction of the total contemporary population (Atkinson 1968; Kinnes 1975). The criteria for inclusion are unclear, but in many instances may have involved elevated social status (Kinnes 1975). In small-scale societies this high status social group might be expected to be disproportionately implicated in instigating warfare and raiding (eg, Reedy-Maschner \& Maschner 1999; Mitchell 1984), but it is not clear that they should therefore be disproportionately represented amongst those found in mortuary monuments. In fact a more likely scenario may be the under-representation of victims of violence between groups. A death occurring away from the community could have presented considerable obstacles to the rapid retrieval of the body for burial. The bodies of victims of a revenge raid could, for example, have been hidden by the perpetrators to delay pursuit. The bodies of slain enemies might be intentionally denied formal burial rites as a further insult. Or the conflict site itself may not have been considered safe for the retrieval of the fallen for days, weeks, or months. And if the body was retrieved or 


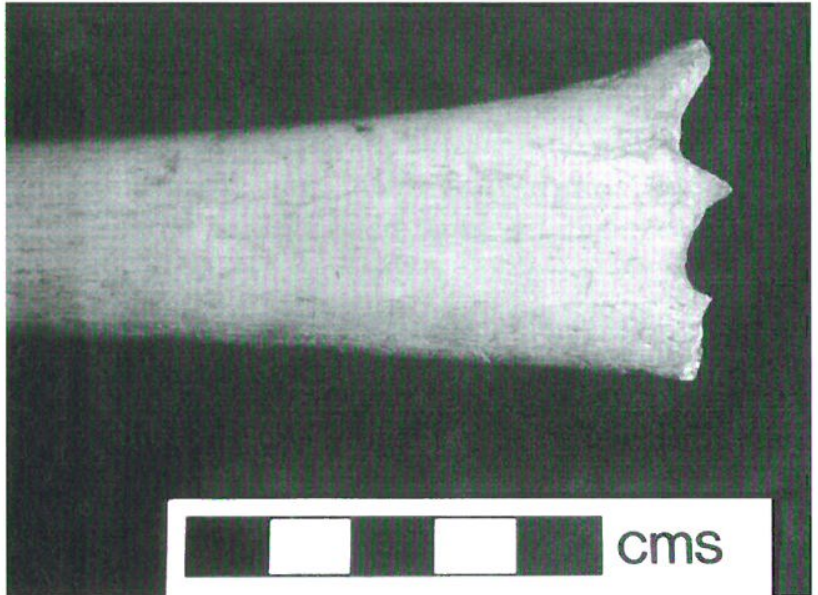

Fig. 23. Distal shaft of human right femur from Bole's Barrow showing typical carnivore gnaw marks (Wiltshire Heritage Museum, Devizes).

returned for burial, what state would it be in? This could offer an alternative explanation to ritual exposure, or excarnation, for the frequently incomplete, sometimes weathered, and occasionally carnivore-scavenged state of human skeletal remains in Neolithic mortuary monuments (Chesterman 1977; Kinnes 1992, 98-103; McKinley forthcoming; Whittle \& Wysocki 1998). Further examples of carnivorescavenged human skeletal material at Bole's Barrow and Wayland's Smithy have been recently identified by the authors (Fig. 23).

Long barrows and chambered tombs are typically seen as the funerary monuments for a local group or lineage: are the victims of violence found in these sites, then, members of the local group, or outsiders? And, if the latter, why would they be accorded what is presumably a high status, formal burial treatment in a monument that only rarely seems to have held all the members of the local group itself? It is worthwhile briefly considering, even if only speculatively, some alternative interpretations. First, it is possible that the individuals in question represent local group members who meet the criteria - whatever they may be - for inclusion in a mortuary monument, and the manner of their death, whether by an enemy or in a more local dispute, is irrelevant. Or perhaps death in the defence of the community or its possessions is one means of achieving the right to burial in a monument. And, as noted by Strathern (1992, 233), overt displays of mourning for a victim of inter-group violence can be used to extort compensation claims from the responsible group. Then, there are various permutations of the interpretation that extends back to Thurnam: 'I hence conclude that the skeletons with cleft skulls are those of human victims immolated on the occasion of the burial of a chief' $(1869,185)$. The chiefly aspect to this view is not an essential component, the essence of which is that the inclusion of a slain enemy with one's own dead is often seen as a propitious act, whether as an appeasement of vengeful ghosts or as a provision of (albeit unwilling) companions in the afterlife.

There are perhaps ways in which these ideas can be explored a bit further. The Staines cranium is reported as having been found with three cervical vertebrae, one reportedly showing cutmarks indicating decapitation (this specimen could not be located). Regardless of the status of the cranial injuries, discussed above, this fact alone strongly suggests that the head was deposited in the ditch segment of the causewayed enclosure in a fleshed state (see CodryCollins 2001; Proulx 2001). Nor is Staines an isolated case. Other examples of skulls with attached vertebrae have been reported in the literature, from Chute I (Passmore 1942), Bole's Barrow, and Tilshead, Wiltshire (Thurnam 1869), Boulevard (Earnshaw 1973), and possibly Whitegrounds, Yorkshire (Brewster 1984). The Boulevard site is particularly intriguing, as a partially burnt skull and atlas vertebra were placed together with a partly polished flint axe at the foot of a large timber post set into a stonepacked pit (Earnshaw 1973). Many more sites report the presence of crania only, though without specifying the presence of associated vertebrae. Conversely, other sites contain skeletons lacking skulls, for example Haddenham, Cambridgeshire (Baxter 1999). Of these sites, we have as yet re-examined only the material from Bole's Barrow, and no compelling evidence for the claimed - again by Thurnam - cuts on the vertebrae has been found. The bone surfaces, however, are difficult to examine properly due to postdepositional damage and to old adhering paper labels. But the direct association of vertebrae with a cranium is itself sufficient to demonstrate that a head was at least partially fleshed when deposited. And this in turn presents the possibility of decapitation, whether performed on a living or recently deceased individual.

The above cases provide a different perspective on a well-known practice in the British Neolithic, that of the circulation and deposition of human remains in 


\section{R. Schulting and M. Wysocki EVIDENCE FOR CRANIAL TRAUMA IN THE BRITISH NEOLITHIC}

mortuary monuments and causewayed enclosures, often interpreted as ancestral relics (Thomas 1988; though see Whitley 2002 for a critique of the concept of 'ancestors'). There are two points to be made here. The first is that human remains need not always have been in a clean, defleshed state when they were manipulated. Baxter (1999) has recently made the same observation through her analysis of the human remains from Haddenham long barrow, documenting the movement of decomposing but still partially articulated bodies. Indeed, the movement and manipulation of elements in various states of decomposition might have specific meanings. The second, and perhaps more contentious, point is that the removal of fleshed heads could be equally interpreted in a discourse of violence rather than as ritual treatment of one's ancestral remains. Indeed, these apparently very different behaviours may actually be two sides of the same coin. When the head is seen as the seat of identity and power it can become a focus for respectful postmortem treatment within one's own group. Equally, when dealing with an enemy, the head may become the focus for acts of violence, and may itself become desirable as a trophy (Keeley 1996, 100). Piggott's (1954, 47) ideas of a head-hunting cult in the British Neolithic may have fallen by the wayside, but there is a certain logic involved. When the physical remains of the 'ancestors', and particularly their skulls, are imbued with power, taking heads can at the very least deny that power to an enemy, and it may even transfer that power to one's own group (Hoskins 1996). The placement of such trophy skulls in structured deposits in causewayed enclosures may well have taken place alongside the deposition of one's own ancestral remains. The acts need not be mutually exclusive: both would impart prestige to the actors involved, and both would enhance a sense of group solidarity (McWilliams 1996). Indeed, as has often been argued, nothing enhances within-group solidarity as much as contrasting it violently with an out-group, the 'other' (Dawson 1996; Schwandner-Sievers 2001; Stewart \& Strathern 2002).

Nor need trophies consist solely of the head. Human skeletal elements are not infrequently encountered in pits or other contexts on various Neolithic sites. Again, these are usually interpreted, if at all, in a discourse of ancestral ritual. Yet there are many ethnographic and historic accounts of the taking of hands, arms, or feet of slain enemies (M.
Smith 1997; Willey 1990). Other trophies could consist of parts of the body that would not survive archaeologically, although they could still leave traces. For example, the most likely explanation for the unusual placement of the cutmarks on the Coldrum cranium exhibiting lethal injuries may be the removal of the ear. They do not conform to diagnostic scalping patterns, and are located away from areas of musculature connecting the mandible with the cranium. There are no other cuts on the cranial vault to indicate defleshing. It is difficult to see this in any other context than the taking of a trophy from a dispatched victim.

Are, then, different types of behaviours being expressed by the healed as opposed to the unhealed injuries? Perhaps in-group and out-group violence can be differentiated in this way, since intra-group conflict leading to death cannot have been often tolerated in small-scale societies. Ethnographic, historic, and modern accounts all frequently emphasise an ideal of relatively peaceful in-group relations, contrasted with socially sanctioned, indeed often highly valued, violence directed at an out-group (Coper-Rougier 1986; Fortune 1939; Paige \& Paige 1981; Schwandner-Sievers 2001; Stewart \& Strathern 2002). This view may be too simplistic however, as, whatever the ideal, lethal interpersonal violence certainly does occur within communities in societies at all levels of socio-cultural complexity. The contexts for this are highly varied, ranging from socially 'tolerated' domestic violence, often, though not always, directed at women, to the punishment of transgression against social norms, such as adultery or sorcery.

Similarly, inter-group violence need not always be deadly in intent or outcome. The high proportion of small, well-healed depressed fractures seen in the British Neolithic could suggest a non-lethal, 'ritualised' context for interpersonal violence, akin to that found among the Yanomami and other groups in many different parts of the world (Abbink 1999; Chagnon 1988; 1997; Halbmayer 2001; Riefenstahl 1973). This possiblity is perhaps strengthened by the generally small size and shallow depth of the British examples. The three injuries to the top of the Fussell's Lodge cranium are in an odd location for face-to-face conflict, and may be an argument for an element of ritualised combat, with specific rules and goals as to legitimate targets on the body. Archaeologically, the high incidence of healed cranial injuries in prehistoric Californian Chumash and northern Chilean 
Chinchorro populations have similarly prompted suggestions of an element of non-lethal combat for dispute resolution (Lambert 1997; Standen \& Arriaza 2000; Walker 1989). Yet, at the same time, it is important to emphasise that ritualised combat is more likely to occur in conjunction with more widespread and more deadly intercommunity violence rather than replacing it, although in some circumstances it may reduce the frequency of larger-scale violent encounters. On the other hand, it may do quite the opposite, as Chagnon (1988; 1997) notes that 'ritualised' combat among the Yanomami often escalates into more deadly and widespread conflict as aggression levels build rather than dissipate (see also Halbmayer 2001).

It is important to note that inter-group violence, even when lethal, does not necessarily indicate the presence of 'warfare', in the sense of organised conflict at the level of autonomous political units. The skeletal evidence for the British Neolithic as it currently stands is inappropriate for this question, and it is again the scale of the defences on a number of causewayed enclosures that constitute the best evidence for something approaching a formal definition of warfare (for definitions, see: Carman 1997; Kelly 2000; Martin \& Frayer 1997; Mercer 1999; Turney-High 1991). Here, the use of the term warfare is justified in the sense that fortification on such a large scale clearly implies a response to organised and directed violence at a sociopolitical level above that of the family or even of the small local group, as opposed to revenge killings or sporadic raiding carried out by individuals or families (Whittle 1996; 2003, 38-9).

One pattern that emerges strongly in the British Neolithic evidence is that men and women are equally represented by both healed and unhealed cranial trauma. Clearly, it would be misguided to suggest that violence against women was restricted to the domestic context. Ethnographic evidence shows that, in a number of societies, women did participate in warfare, both as aggressors and as victims (Ewers 1994), although more commonly as the latter (Keeley 1996; Larradale 1998). In North American Plains and Papua New Guinean Highland societies, as well as elsewhere, when a revenge killing was sought, it mattered little whether the victim was male or female, adult or child. Generally they were simply in the wrong place at the wrong time, or presented little risk to the assailant/s (Gardner \& Heider 1974; Hoskins
1996; Rosaldo 1980). Turning to archaeological evidence of cranial trauma elsewhere in the world, we also see the representation of both males and females, in widely varying proportions. On the Northern Plains of North America, men and women appear to have been at more or less equal risk of being killed and scalped during late prehistory (Owsley 1994). In Aboriginal Australia, generally far more females than males show cranial fractures: $27.3 \%$ vs $16.7 \%$ overall, combining a series of samples (Webb 1995, table 8-2). Although some of these cranial injuries might be self-inflicted during mourning rites, as documented in ethnographic accounts (Webb 1995, 202), it is still clear that conflict between men and women, and between women and women, occurred in Australia. The capture of women is on occasion another goal of warfare in small-scale societies (Donald 1997; Otterbein 2000), and there may even be evidence of this at the Early Neolithic (LBK) site of Asparn/Schletz in Austria (Gronenborn 2001; Teschler-Nicola et al. 1996). The relationship between gender and violence in prehistoric Europe is a topic that requires further investigation (see Robb 1997).

\section{Motivation and violent performances}

Many motivations for inter-group violence in smallscale societies have been proposed and debated, including innate aggression, the desire for revenge, material gain, the capture of women, and the acquisition of status (Cannon 1992; Donald 1997; Ember \& Ember 1997; Ferguson 1984; Haas 1990; Martin \& Frayer 1997; Maschner 1997; Mitchell 1984). Revenge and plunder seem to be strong emic motivations for warfare in non-state level societies (Keeley 1996, tables 8.1, 8.2). Raiding is particularly common in pastoral societies, since the objects of the raid may be taken 'on the hoof'. Furthermore, animals in pastoral societies typically represent both economic wealth and social prestige, making them very attractive targets. Cereals, on the other hand, in addition to being rather awkward to carry away in bulk, rarely have the same connotations. Indeed, the term 'pastoral' is a curious choice with which to invoke images of a peaceful rural idyll, as pastoral societies are often prone to endemic raiding and warfare (Barfield 1993; Keeley 1996; Lucas 1989; Fukai \& Turton 1979; Turney-High 1991). When wealth is in the form of animals, it frequently presents too tempting a target to refuse (cf. Mercer 1989a). And in such contexts, raiding can take on strong 


\section{R. Schulting and M. Wysocki EVIDENCE FOR CRANIAL TRAUMA IN THE BRITISH NEOLITHIC}

cultural associations, conferring adult status, gender identity, high social standing, and a sense of personal worth (Evans-Pritchard 1940; Lucas 1989; Patterson 1994; Richards 1932). It is of course not intended to attribute all of these characteristics to the British Neolithic. But the recent emphasis on the importance of cattle-keeping does suggest that we should be thinking more about the consequences of this way of life, particularly as this is one of the few points of consensus in the ongoing debates concerning the role of domestic animals in earlier Neolithic Britain (eg, Barclay \& Hey 1999; Caulfield 1983; Ray \& Thomas 2003; Schulting 1998; 2004; Stallibrass \& Huntley 1996; Thomas 1999; Thorpe 1984; Tresset 2000; Whittle \& Pollard 1998). And these consequences include, we would suggest, the possibility of endemic, if normally small-scale, raiding and conflict.

Motivations for intra-group conflict have perhaps received less anthropological attention, and appear to be more ambiguous. The negotiation of gender and age relationships are an obvious arena for interpersonal violence as social action. Male gender identity may be bound up with projecting an image of potential violence that needs to be enacted within the group on occasion to be re-inforced. Sexual jealousies, perceived slights or stinginess, small thefts, damage caused by a neighbour's animals to one's crops, all of these and others are potential sources of tension within the group that can lead to outbursts of violence. The classic hunter-gatherer response to such tensions, to physically move away for a period of time, is less of an option to those committed to a farming/herding way of life (while ongoing debate on this issue is acknowledged, one of the authors has argued elsewhere that the transition to farming in Neolithic Britain was indeed swift and complete (eg, Richards et al. 2003; Schulting 2004; see also RowleyConwy 2004)).

Linking both inter- and intra-group violence is its powerful performative aspect. The performative aspect of social action has recently been emphasised in discussions of British prehistory (eg, Barrett 1994). It has been strongly linked, for example, with death through mortuary rituals, though rarely with the nature of that death. But what has not been acknowledged is that violence constitutes one of the most powerful performances imaginable, and as such is an highly effective means of maintaining or transforming the social environment and staging an ideological message before a public audience
(Schröder \& Schmidt 2001, 6; see also Riches 1986; Schechner 1993; Whitehead 2002). Violence directed against the 'outsider' often serves to more tightly define the in-group, while violence within the group can be used at various levels to coerce and intimidate others, and to define identities and social positions. Within-group violence can provide a powerful adjunct to other avenues to social power-ritual, social, economic, etc, - maintaining, or challenging, more local relations of power, whether considered at the level of the community as a whole (however that may be defined), or at that of the smallest domestic unit (eg, the 'family'). The prevalence of interpersonal violence affecting the cranium in the British Neolithic, while not unusually high, is sufficient that most people would have been personally aware of someone who had been involved in such an incident, whether lethal or not. The fear of violence can have affects far out of proportion to its actual prevalence (cf. Whitehead 2002). And larger scale violent events, such as Talheim in Germany, or the attacks on causewayed enclosures such as Hambledon Hill, Crickley Hill, and Carn Brea, would generate much longer-term memories that could resonate through generations, invoking what has been termed the 'violent imaginary' (Schröder \& Schmidt 2001). Thus, there would be an awareness of the potential of violence at various levels as a form of social action. Connecting the two contexts for violence - out-group and in-group - could be the positive sociocultural valuation of violence as an appropriate means of conflict resolution in certain situations.

The actuality or threat - or promise, for violence is certainly not always perceived as being in any way negative, as least by some segments of a society - of violence can have major consequences for human behaviour, both that of the aggressor and that of the (intended) recipient, and both at the individual and the group level. To conclude with one example, the threat of violence may have served as one check to the scenario of high mobility that has recently come to dominate views of earlier Neolithic settlement in Britain (Bradley 1987; Thomas 1999; Whittle 1996; 1997; the situation in Ireland seems to have been qualitatively different - Cooney 2000). This would have become more and more a factor as the landscape became increasingly populated, or, more importantly, became increasingly subject to claims of, and conflicts over, ownership and use-rights. It is a rare situation ethnographically in which individuals are able to 
travel across the wider 'landscape' (ie, the territories of other groups) as freely as much of the current writing on the British Neolithic would seem to imply (Coper-Rougier 1986, 57; Meggitt 1977, 44-5). This is emphatically not to deny the abundant evidence for long-distance exchanges, particularly seen with stone axes (Bradley \& Edmonds 1993; Edmonds 1995), or, more recently, in the isotopic evidence for the movement of individuals over the course of their lifetimes (Montgomery et al. 2000), but rather to suggest a fuller appreciation of the social contexts in which such exchanges and movements may have taken place.

It has long been a truism in anthropology that groups that fight also exchange, both materials and marriage partners (Codere 1950; Lévi-Strauss 1944). These exchanges are often intended to create or maintain social bonds between groups. This is not done for its own sake, but for a reason, and a not uncommon reason involves the creation and maintenance of alliances, both economic and military (Burton 1987; Hayano 1974). And alliances, particularly those among a complex web of small and autonomous communities with what might be termed an intermediate concentration of leadership ('transegalitarian' in Hayden's (1996) terminology), often shift and break down. Thus, there is not necessarily any discrepancy between the evidence for exchange in Neolithic Britain, and the proposal that movement beyond the confines of one's social group may have been imbued with an element of risk. Groups that exchange axes and marriage partners one day, may fight the next. Indeed, perceived slights in these exchanges (failure to pay brideprice for example) are very often the pretext for the rapid switch from one set of social relations to the other (Pospisil 1994).

Furthermore, at least with regards to the exchange of materials, the risks involved in the acquisition of certain items may have been an inherent part of their desirability. Bradley (Bradley 1993; 2000, 85-8; Bradley \& Ford 1986) has convincingly argued that the choice of some of the most inaccessible rock faces at Langdale for quarrying relates to the increased value attributed to axes made of such stone. Similar reasoning can be applied to the acquisition of stone axes from distant sources - it is, in part, the element of danger involved that makes such exotic items of increased value (Helms 1988). The ability to obtain material from a geographically, and socially, distant source despite the potential risks, enhances the prestige of those able to do so. Nor, it might be added, need this apply only to materials. The movement of people, for which evidence is emerging (Montgomery et al. 2000), need not always be voluntary.

There is, of course, also the element of time to be considered. There may have very well been long periods during which the movement of objects and people posed less risk than at other times; we are after all condensing a period of some 800 years when speaking of the 'earlier Neolithic'. The evidence presented here could either suggest constant and relatively low levels of interpersonal violence, or certain periods of time with considerably heightened incidents of violence, as has been suggested by some for the end of the earlier Neolithic (Bradley 1984; Hodder 1990, 260; see also Whittle 2003, 38). It is not at present possible to choose between these alternatives, and a programme of targeted AMS dating is required to explore the intriguing possibility of variation in this respect.

\section{CONCLUSION}

This is admittedly only a first step towards understanding the prevalence, contexts, causes, and possible consequences of interpersonal violence. But we hope to have shown that there is more material to work with than has been previously appreciated. Analysis of human skeletal collections from the earlier Neolithic of mainly southern Britain has revealed evidence for trauma on 31 of 350 crania. Some of these examples remain uncertain indicators of interpersonal violence - either because of doubts over their identification as peri-mortem fractures, or because some might reflect accidents - and so we suggest figures of about $2 \%$ peri-mortem trauma (ie, themselves lethal, or part of a suite of lethal injuries), and $4-5 \%$ healed trauma. The sexes are approximately equally represented in both lethal and non-lethal violence. There are some tentative hints that different contexts may be implicated by healed and unhealed trauma, in that unhealed injuries seem more concentrated on the left side of the cranium, suggesting face-to-face conflict. The injuries represented range from rather light blows to the head, some possibly reflecting domestic or ritualised contexts for conflict, to multiple lethal injuries that may reflect the 'over-kill' of external enemies or of 


\section{R. Schulting and M. Wysocki EVIDENCE FOR CRANIAL TRAUMA IN THE BRITISH NEOLITHIC}

serious transgressors within the group. There is evidence for the deposition of fleshed heads, in one case possibly associated with a violent death, that suggests that the removal and circulation of heads could be considered in a discourse of violence alongside the inevitable one of ancestor worship.

Many questions remain, in particular those relating to variability in the prevalence of interpersonal violence within different regions (and at different times) of Britain and Ireland, as well as within the wider European context. Only within this broader comparative framework will it be possible to situate the British Neolithic evidence as 'low' or 'high' - the ethnographic data are not appropriate points of comparison for this aspect of archaeological assemblages, since many violent deaths will not leave traces on the skeleton, particularly when dealing with partial and fragmentary material. Nevertheless, the skeletal evidence provides an important line of inquiry into the prevalence, nature, and contexts for interpersonal violence in prehistory, one that has been under-utilised. Violence is not an aberrant act; rather, it can constitute an effective performance in a number of situations. In whatever degree and manner it is expressed, violence is a feature of social life, and plays a strong role in structuring both society and individual experience. The data and discussion presented here are intended to contribute towards a dialogue that takes into consideration this very real and powerful aspect of human interaction.

Acknowledgements: Earlier versions of this paper were presented at the Sheffield conference 'Violence and warfare in prehistory and protohistory', and at the 4th meeting of the British Association of Biological Anthropology and Osteoarchaeology, and we thank participants at both for their comments. The following individuals facilitated access to collections in their care, for which we are very grateful: Maggie Bellatti and Rob Foley at the Duckworth Laboratory, Cambridge; Julien Parsons at the Cheltenham Museum and Art Gallery; Paul Robinson at the Wiltshire Heritage Museum, Devizes; Elizabeth Walker at the National Museum and Gallery of Wales, Cardiff; Ian Whitehead at the Hartlepool Museum; Gillian Varndell at the British Museum; Rob Kruszinski and Louise Humphrey at the Natural History Museum, London; and David Pearson and Jill Greenaway at the Museum of Reading. We are grateful to Michael Tooley for providing information and documentation concerning the Hartlepool skeleton, and to Jackie McKinley for permission to cite unpublished information on Hambledon Hill. Thanks to Bob Pastor for information about keyhole wounds, and to Chris Knüsel, Joanna Ostapkowicz, and Alasdair Whittle for their comments on an earlier version of this paper. Comments by two anonymous reviewers are also much appreciated. We gratefully acknowledge the Prehistoric Society (RJS) and the Leverhulme Trust (MW) for their support in this research.

\section{BIBLIOGRAPHY}

Abbink, J. 1999. Violence, ritual and reproduction: culture and context in Surma duelling. Ethnology 38, 227-42

Alvrus, A. 1999. Fracture patterns among the Nubians of Semna South, Sudanese Nubia. International Journal of Osteoarchaeology 9, 417-29

Arnott, R., Finger S. \& Smith, C.U.M. (eds), Trepanation: history, discovery, theoy. Lisse: Swets \& Zeitlinger

Atkinson, R.J.C. 1965. Wayland's Smithy. Antiquity 39, $126-33$

Atkinson, R.J.C. 1968. Old mortality: some aspects of burial and population in Neolithic England. In J.M. Coles \& D.D.A. Simpson (eds), Studies in Ancient Europe: essays presented to Stuart Piggott, 83-93. Leicester: University Press

Barclay, A. \& Hey, G. 1999. Cattle, cursus monuments and the river: the development of ritual and domestic landscapes in the Upper Thames Valley. In A. Barclay \& J. Harding (eds), Pathways and Ceremonies: the cursus monuments of Britain and Ireland, 67-76. Oxford: Oxbow

Barfield, T.J. 1993. The Nomadic Alternative. Englewood Cliffs, New Jersey: Prentice-Hall

Barrett, J.C. 1994. Fragments from Antiquity. Oxford: Blackwell

Baxter, M. 1999. Dancing with the dead in a mass grave. British Archaeology 50, 6-7

Bennett, F.J. 1913. Coldrum monument and exploration 1910. Journal of the Royal Anthropological Institute 43, 76-85

Bennike, P. 1985. Palaeopathology of Danish Skeletons. Copenhagen: Akademisk Forlag

Bennike, P. 2003. Ancient trepanations and differential diagnoses: a re-evaluation of skeletal remains from Denmark. In Arnott et al. (eds) 2003, 95-115

Berryman, H.E. \& Haun, S.J. 1996. Applying forensic techniques to interpret cranial fracture patterns in an archaeological specimen. International Journal of Osteoarchaeology 6, 2-9

Berryman, H.E., Smith, O.C. \& Symes, S.A. 1995. Diameter of cranial gunshot wounds as a function of bullet caliber. Journal of Forensic Sciences 40, 751-4

Bird, H. 1865. An account of the human bones found in the round and long tumuli, situated on the Cotswold Hills, near Cheltenham. Journal of the Anthropological Society $3,65-74$

Bradley, R. 1984. The Social Foundations of Prehistoric Britain. New York: Longman

Bradley, R. 1986. A reinterpretation of the Abingdon causewayed enclosure. Oxoniensia 51, 183-7

Bradley, R. 1987. Flint technology and the character of Neolithic settlement. In A.G. Brown \& M.R. Edmonds (eds), Lithic Analysis and Late British Prehistory, 181-5. 
Oxford: British Archaeological Report 162

Bradley, R. 1993. Altering the Earth: the origins of monuments in Britain and Continental Europe. Edinburgh: Society of Antiquaries of Scotland

Bradley, R. 1998. Interpreting enclosures. In M. Edmonds \& C. Richards (eds), Understanding the Neolithic of NorthWestern Europe, 188-203. Glasgow: Cruithne Press

Bradley, R. 2000. An Archaeology of Natural Places. London: Routledge

Bradley, R. \& Edmonds, M. 1993. Interpreting the Axe Trade. Cambridge: University Press

Bradley, R. \& Ford, S. 1986. The siting of Neolithic stone quarries: experimental archaeology at Great Langdale, Cumbria. Oxford Journal of Archaeology 5, 123-8

Brewster, T.C.M. 1984. The Excavation of Whitegrounds Barrow, Burythorpe. Wintringham: John Gent

Brothwell, D.R. 1961. The palaeopathology of early British man: an essay on the problems of diagnosis and analysis. Journal of the Royal Anthropological Institute 91, 318-44

Brothwell, D.R. 2003. The future direction of research. In Arnott et al. (eds) 2003, 365-72

Brothwell, D.R. \& Blake, M.L. 1966. The human remains from Fussell's Lodge long barrow: their morphology, discontinuous traits and pathology. Archaeologia 100, 48-63

Brothwell, D.R. \& Cullen, R. 1991. The human bone. In A. Whittle, Wayland's Smithy, Oxfordshire: excavations at the Neolithic tomb in 1962-63 by R.J.C. Atkinson and S. Piggott. Proceedings of the Prehistoric Society 57(2), $72-80$

Burton, J. 1987. Exchange pathways at a stone axe factory in Papua New Guinea. In G. de G. Sieveking \& M. Newcomer (eds), The Human Uses of Flint and Chert, 183-91. Cambridge: University Press

Camps, F.E., Chandra, H. \& Dawes, J.D. 1987. Human bone. In R. Robertson-Mackay, The Neolithic causewayed enclosure at Staines, Surrey: excavations 1961-63. Proceedings of the Prehistoric Society 53, appendix 6, 6-20

Cannon, A. 1992. Conflict and salmon on the Interior Plateau of British Columbia. In B. Hayden (ed.), A Complex Culture of the British Columbia Plateau: Traditional Stl'átl'imx Resource Use, 506-24. Vancouver: UBC Press

Carman, J. (ed.) 1997. Material Harm: archaeological studies of war and violence. Glasgow: Cruithne Press

Caulfield, S. 1983. The Neolithic settlement of North Connaught. In T. Reeves-Smyth \& F. Hammond (eds), Landscape Archaeology in Ireland, 195-216. Oxford: British Archaeological Report 116

Chagnon, N.A. 1988. Life histories, blood revenge, and warfare in a tribal population. Science 239, 985-92

Chagnon, N.A. 1997. Yanomamö. Orlando: Harcourt Brace 5 th edn

Chapman, J. 1999. The origins of warfare in the prehistory of central and eastern Europe. In J. Carman \& A. Harding (eds), Ancient Warfare, 101-42. Stroud: Sutton

Chege, N., Sartoris, D.J., Tyson, R. \& Resnick, D. 1996.
Imaging evaluation of skull trepanation using radiography and CT. International Journal of Osteoarchaeology 6, 249-58

Chesterman, J.T. 1977. Burial rites in a Cotswold long barrow. Man N.S. 12, 22-32

Cleal, R.M.J., Walker, K.E \& Montague, R. 1995. Stonehenge in its Landscape. London: English Heritage Archaeological Report 10

Clark, J.G.D. 1963. Neolithic bows from Somerset, England, and the prehistory of archery in north-western Europe. Proceedings of the Prehistoric Society 29, 50-98

Codere, H. 1950. Fighting with Property. Seattle: University of Washington Press

Codry-Collins, A. 2001. Decapitation in Cupisnique and Early Moche societies. In E. Benson \& A.G. Cook (eds), Ritual Sacrifice in Ancient Peru, 21-33. Austin: University of Texas Press

Coles, J.M. 1977. Parade and display: experiments in Bronze Age Europe. In V. Markotic (ed.), Ancient Europe and the Mediterranean: studies in honour of Hugh Hencken, 51-8. Warminster: Aris \& Phillips

Coles, J.M., Hibbert, F.A. \& Orme, B.J. 1973. Prehistoric roads and tracks in Somerset, England: 3. The Sweet Track. Proceedings of the Prehistoric Society 39, 256-93

Cooney, G. 2000. Landscapes of Neolithic Ireland. London: Routledge

Coper-Rougier, E. 1986. 'Le Mal Court': visible and invisible violence in an acephalous society - Mkako of Cameroon. In D. Riches (ed.), The Anthropology of Violence, 50-69. Oxford: Blackwell

Corcoran, J.X.W.P. 1967. Excavation of three chambered cairns at Loch Calder, Caithness. Proceedings of the Society of Antiquaries of Scotland 98, 1-75

Crawford, O.G.S. 1925. The Long Barrows of the Cotswolds. Gloucester

Dawson, D. 1996. The origins of war: biological and anthropological theories. History and Theory 35, 1-28

Darbishire, R.D. 1874. Notes on discoveries in Ehenside Tarn, Cumberland. Archaeologia 44, 273-92

DiMaio, V.J.M. 1999. Gunshot Wounds: practical aspects of firearms, ballistics and forensic techniques. Boca Raton: CRC Press

Dixon, P. 1988. The Neolithic settlements on Crickley Hill. In C. Burgess, P. Topping, C. Mordant \& M. Maddison (eds), Enclosures and Defences in the Neolithic of Western Europe, 75-87. Oxford: British Archaeological Report S403

Donald, L. 1997. Aboriginal Slavery on the Northwest Coast of North America. Berkeley \& Los Angeles: University of California Press

Earnshaw, J.R. 1973. The site of a medieval post mill and prehistoric site at Bridlington. Yorkshire Archaeological Journal 45, 19-40

Edmonds, M.R. 1995. Stone Tools and Society: working stone in Neolithic and Bronze Age Britain. London: Batsford

Edmonds, M.R. \& Thomas, J. 1987. The Archers: an everyday story of country folk. In A.G. Brown \& M. Edmonds (eds), Lithic Analysis and Later British 


\section{R. Schulting and M. Wysocki EVIDENCE FOR CRANIAL TRAUMA IN THE BRITISH NEOLITHIC}

Prehistory, 187-99. Oxford: British Archaeological Report 162

Elton, H. 1996. Warfare in Roman Europe AD 350-425. Oxford: Clarendon

Ember, C.R. \& Ember, M. 1997. Violence in the ethnographic record: results of cross-cultural research on war and aggression. In Martin \& Frayer (eds) 1997, 1-20

Evans-Pritchard, E.E. 1940. The Nuer. Oxford: Clarendon

Everton, A. \& Everton, R. 1972. Hay Wood Cave burials, Mendip Hills, Somerset. Proceedings of the University of Bristol Spelaeological Society 13, 5-29

Ewers, J.C. 1994. Women's roles in Plains Indian warfare. In D.W. Owsley \& R. Jantz (eds), The Skeletal Biology of the Plains, 325-32. Washington, D.C.: Smithsonian Institution Press

Ferguson, R.B. 1984. Introduction: studying war. In R.B. Ferguson (ed.), Warfare, Culture and Environment, 1-81. New York: Academic

Fortune, R. 1939. Arapesh warfare. American Anthropologist 41, 22-41

Fukai, K. \& Turton, D. (eds). 1979. Warfare Among East African Herders. Osaka: National Museum of Ethnology

Gardner, R. \& Heider, K.G. 1974. Gardens of War. Harmondsworth: Penguin

Garson, J.G. 1905. On the crania and other human remains found in the barrow at Howe Hill (no. 273), Duggleby. In J.R. Mortimer, Forty Years' Researches in British and Saxon Burial-Mounds of East Yorkshire, 30-9. London: A. Brown

Gat, A. 1999. The pattern of fighting in simple, small-scale, prestate societies. Journal of Anthropological Research $55,563-83$

Gibson, A.M. \& Simpson, D.D.A. 1987. Lyles Hill, Co. Antrim. Archaeology Ireland 1, 72-5

Green, C., Bellwood, P., Hammond, N. \& Case, H. 1970. Neolithic comments. Antiquity 44, 105-14

Green, H.S. 1980. The Flint Arrowheads of the British Isles. Oxford: British Archaeological Report 75

Greenwell, W. 1877. British Barrows. Oxford: Clarendon

Gronenborn, D. 2001. Zum (möglichen) Nachweis von Sklaven/Unfreien in prähistorischen Gesellschaften Mitteleuropas. Ethnographische-Archäologische Zeitschrift 42, 1-42

Gurdjian, E.S., Webster, J.E. \& Lissner, H.R. 1950. The mechanism of skull fracture. Radiology 54, 313-39

Halbmayer, E. 2001. Socio-cosmological contexts and forms of violence: war, vendetta and suicide among the Yukpa or north-western Venezuela. In B.E. Schmidt \& I.W. Schröder (eds), Anthropology of Violence and Conflict, 50-75. London: Routledge

Haas, J. (ed.) 1990. The Anthropology of War. Cambridge: University Press

Haas, J. \& W. Creamer. 1997. Warfare among the pueblos: myth, history, and ethnography. Ethnohistory 44, 235-61

Hayano, D.M. 1974. Marriage, alliance, and warfare: a view from the New Guinea Highlands. American Ethnologist 1, 281-93

Hayden, B. 1996. Thresholds of power in emergent complex societies. In J. Arnold (ed.), Emergent Social Complexity,
50-58 Ann Arbor: International Monographs in Prehistory

Helms, M.W. 1988. Ulysses' Sail. Princeton: University Press Hodder, I. 1990. The Domestication of Europe. Oxford: Blackwell

Hoskins, J. 1996. Introduction: headhunting as practice and as trope. In J. Hoskins (ed.), Headhunting and the Social Imagination in Southeast Asia, 1-49. Stanford: University Press

Huddart, D., Gonzalez, S. \& Roberts, G. 1999. The archaeological record and mid-Holocene marginal coastal palaeoenvironments around Liverpool Bay. Quaternary Proceedings 7, 563-74

Jurmain, R. 1999. Stories from the Skeleton: behavioural reconstruction in human osteology. New York: Routledge Jurmain, R. 2001. Paleoepidemiolgical patterns of trauma in a prehistoric population from central California. American Journal of Physical Anthropology 115, 13-23

Jurmain, R. \& Bellifemine, V.I. 1997. Patterns of cranial trauma in a prehistoric population from Central California. International Journal of Osteoarchaeology 7, 43-50

Kaufman, M.H., Whitaker, D. \& McTavish, J. 1997. Differential diagnosis of holes in the calvarium: application of modern clinical data to palaeopathology. Journal of Archaeological Science 24, 193-218

Keeley, L.H. 1996. War Before Civilization: the myth of the peaceful savage. Oxford: University Press

Kelly, R.C. 2000. Warless Societies and the Origins of War. Ann Arbor: University of Michigan Press

Kinnes, I. 1975. Monumental function in British Neolithic burial practices. World Archaeology 7, 16-29

Kinnes, I. 1992. Non-Megalithic Long Barrows and Allied Stuctures in the British Neolithic. London: British Museum Occasional Paper 52

Knight, B. 1991. Forensic Pathology. London: Edward Arnold

Lambert, P.M. 1997. Patterns of violence in prehistoric hunter-gatherer societies of coastal southern California. In Martin \& Frayer (eds) 1997, 77-110

Larradale, S. 1998. The context of Early Puebloan violence. In P.Y. Bullock (ed.), Deciphering Anasazi Violence, 11-33. Santa Fe: HRM Books

Lévi-Strauss, C. 1944. Guerre et commerce chex Indiens de l'Amerique du Sud. Renaissance 1, 122-39

Liddell, D.M. 1935. Report on the excavations at Hembury Fort, Devon (fourth and fifth seasons 1934 and 1935). Proceedings of the Devon Archaeological Exploration Society 2, 135-75

Logue, P. 2003. Excacations at Thornhill, Co. Londonderry. In I. Armit, E. Murphy, E. Nelis \& D. Simpson (eds), Neolithic Settlement in Ireland and Western Britain, 149-55. Oxford: Oxbow

Lovell, N.C. 1997. Trauma analysis in paleopathology. Yearbook of Physical Anthropology 40, 139-70

Lucas, A.T. 1989. Cattle in Ancient Ireland. Kilkenny: Boethius

Lynch, A. 1988. Poulnabrone - A stone in time ... Archaeology Ireland 2, 105-7

Lynch, A. \& Ó Donnabháin, B. 1994. Poulnabrone portal 
tomb. The Other Clare 18, 5-7

Mallory, J.P. \& Hartwell, B. 1984. Donegore. Current Archaeology 92, 271-5

Maples, W.R. 1986. Trauma analysis by the forensic anthropologist. In K.J. Reichs (ed.), Forensic Osteology: advances in the identification of human remains, 218-28. Springfield: Charles C. Thomas

Martin, D.L. \& Frayer, D.W. (eds). 1997. Troubled Times: violence and warfare in the past. Amsterdam: Gordon \& Breach

Martin, G. 2003. Why trepan? Contributions from medical history and the South Pacific. In Arnott et al. (eds) 2003, 323-45

Maschner, H.D.G. 1997. The evolution of northwest coast warfare. In Martin \& Frayer (eds) 1997, 267-302

McKinley, J.I. forthcoming. Human remains. In R.J. Mercer \& F. Healy (eds), Hambledon Hill, Dorset, England. Excavation and Survey of a Neolithic Monument Complex and its Surrounding Landscape. Swindon: English Heritage Archaeological Reports

McWilliams, A. 1996. Severed heads that germinate the state. In J. Hoskins (ed.), Headhunting and the Social Imagination in Southeast Asia, 127-66. Stanford: University Press

Meggitt, M. 1977. Blood is their Argument: warfare among Mae Enga tribesmen of the New Guinea Highlands. Palo Alto: Mayfield Press

Mercer, R.J. 1980. Hambledon Hill: a Neolithic landscape. Edinburgh: University Press

Mercer, R.J. 1986. The Neolithic in Cornwall. Cornish Archaeology 25, 35-80

Mercer, R.J. 1988. Hambledon Hill, Dorest, England. In C. Burgess, P. Topping, C. Mordant \& M. Maddison (eds), Enclosures and Defences in the Neolithic of Western Europe, 89-106. Oxford: British Archaeological Report S403

Mercer, R.J. 1989a. The earliest defences in western Europe. Part 1. Fortress 2, 16-22

Mercer, R.J. 1989b. The earliest defences in western Europe. Part 2. Fortress 3, 2-11

Mercer, R.J. 1990. The inception of farming in the British Isles and the emergence of Indo-European languages in NW Europe. In T.L. Markey \& J.A.C. Greppen (eds), When Worlds Collide: Indo-Europeans and Pre-IndoEuropeans, 101-14. Ann Arbor: Karoma

Mercer, R.J. 1999. The origins of warfare in the British Isles. In J. Carman \& A. Harding (eds), Ancient Warfare, 143-56. Stroud: Sutton

Mitchell, D. 1984. Predatory warfare, social status, and the North Pacific slave trade. Ethnology 23, 39-48

Montgomery, J., Budd, P. \& Evans, J. 2000. Reconstructing the lifetime movements of ancient people: a Neolithic case study from southern England. Journal of European Archaeology 3, 370-85

Musgrave, G. 1857. Solway Moss. Proceedings of the Society of Antiquaries 4, 112-13

Novak, S.A. 2000. Battle-related trauma. In V. Fiorato, A. Boylston \& C. Knüsel (eds), Blood Red Roses: the archaeology of a mass grave from the Battle of Towton AD
1461, 90-102. Oxford: Oxbow

Ortner, D.J. 2003. Identification of Pathological Conditions in Human Skeletal Remains. London: Academic (2nd edn)

Ortner, D.J. \& Aufderheide, A.C. (eds). 1991. Human Paleopathology: current synthesis and future options. Washington, D.C.: Smithsonian Institution Press

Ortner, D.J. \& Putschar, W.G.J. 1985. Identification of Pathological Conditions in Human Skeletal Remains. Washington, D.C.: Smithsonian Institution Press

Oswald, A., Dyer, C. \& Barber, M. 2001. The Creation of Monuments: Neolithic causewayed enclosures in the British Isles. Swindon: English Heritage

Otterbein, K.F. 1968. Internal war: a cross-cultural study. American Anthropologist 70, 277-289.

Otterbein, K.F. 1999. A history of research on warfare in anthropology. American Anthropologist 101, 794-805

Otterbein, K.F. 2000. Killing of captured enemies: a crosscultural study. Current Anthropology 41, 439-43

Owsley, D.W. 1994. Warfare in coalescent tradition populations of the Northern Plains. In D.W. Owsley \& R. Jantz (eds), The Skeletal Biology of the Plains, 333-43. Washington, D.C.: Smithsonian Institution Press

Paige, K.E. \& Paige, J.M. 1981. The Politics of Reproductive Ritual. Berkeley: University of California Press

Parker, S., Roberts, C. \& Manchester, K. 1986. A review of British trepanations with reports on two new cases. Ossa $12,141-57$

Passmore, A.D. 1942. Chute, barrow I. Wiltshire Archaeological Magazine 50, 100-1

Patterson, N. 1994. Cattle Lords and Clansmen. Notre Dame, Indiana: University Press

Péquart, M. \& Péquart, S.-J. 1954. Hoëdic, Deuxième Station-Nécropole du Mésolithique Côtier Armoricain. Anvers: De Sikkel

Piggott, S. 1948. The excavations at Cairnpapple Hill, West Lothian, 1947-48. Proceedings of the Society of Antiquaries of Scotland 82, 68-123

Piggott, S. 1954. The Neolithic Cultures of the British Isles. Cambridge: University Press

Piggott, S. 1962. The West Kennet Long Barrow. London: HMSO

Pitt-Rivers, A.L.F. 1898. Excavations at Cranborne Chase, Vol. IV. Privately printed

Pospisil, L. 1994. 'I am very sorry I cannot kill you any more': war and peace among the Kapauku. In S.P. Reyna \& R.E. Downs (eds), Studying War: anthropological perspectives, 113-26 Reading: Gordon \& Breach

Proulx, D.A. 2001. Ritual uses of trophy heads in ancient Nasca society. In E. Benson \& A.G. Cook (eds), Ritual Sacrifice in Ancient Peru, 119-36. Austin: University of Texas Press

Pryor, F. 1976. A Neolithic multiple burial from Fengate. Antiquity 50, 232-3

Quatrehomme, G. \& Isçan, M.Y. 1998. Analysis of beveling in gunshot entrance wounds. Forensic Science International 93, 45-60

Quatrehomme, G. \& Isçan, M.Y. 1999. Characteristics of gunshot wounds in the skull. Journal of Forensic Sciences 
some current research, 41-60. Oxford: British Archaeological Report 133

Thorpe, I.J. 2003. Anthropology, archaeology, and the origin of war. World Archaeology 35, 145-65

Thurnam, J. 1856. On a cromlech-tumulus called Lugbury, near Littleton Drew. Wiltshire Archaeological Magazine 3, 164-77

Thurnam, J. 1865. On the two principal forms of ancient British and Gaulish skulls. Part II. Memoirs of the Anthropological Society 1865, 459-519

Thurnam, J. 1869. On ancient British barrows (Part I. Long barrows). Archaeologia 42, 161-244

Tooley, M.J. 1978. The history of Hartlepool Bay. International Journal of Nautical Archaeology 7, 71-5

Treherne, P. 1995. The warrior's beauty: the masculine body and self-identity in Bronze-Age Europe. Journal of European Archaeology 3, 105-44

Tresset, A. 2000. Early husbandry in Atlantic areas. Animal introductions, diffusions of techniques and native acculturation at the north-western fringe of Europe. In J.C. Henderson (ed.), The Prehistory and Early History of Atlantic Europe, 17-32. Oxford: British Archaeological Report S861

Turner, A., Gonzalez, S. \& Ohman, J.C. 2002. Prehistoric human and ungulate remains from Preston Docks, Lancashire, UK: problems of river finds. Journal of Archaeological Science 29, 423-33

Turney-High, H.H. 1991. Primitive War: its practice and concepts: University of South Carolina Press (3rd edn)

Vandkilde, H. 2003. Commemorative tales: archaeological responses to modern myth, politics and war. World Archaeology 35, 126-44

Vencl, H. 1984. War and warfare in archaeology. Journal of Anthropological Archaeology 3, 116-32

Verano, J.W. 1997. La trepanación como tratamiento terapeútico en el antiguo Peru. In R. Ramos Rodríguez \& E. Peña Reyes (eds), Estudios de Antropología Biológica Volumen VIII, 65-81. Mexico: Universidad Nacional Autónoma de México/Instituto de Investigaciones Antropológicas

Verano, J.W. 2003. Trepanation in prehistoric South America: geographic and temporal trends over 2,000 years. In Arnott et al. (eds) 2003, 223-36

Villa, P. \& Mahieu, E. 1991. Breakage patterns of human long bones. Journal of Human Evolution 21, 27-48

Vutiropulos, N. 1991. The sling in the Aegean Bronze Age. Antiquity 65, 279-86

Wahl, J. \& König, H. 1987. AnthropologischTraumologische Untersuchung der Menschlichen Skelettreste aus dem Bandkeramischen Massengrab bei Talheim, Kreis Heilbronn. Fundberichte was BadenWurtemberg 12, 65-193

Wakely, J. 1997. Identification and analysis of violent and non-violent head injuries in osteo-archaeological material. In J. Carman (ed.), Material Harm: archaeological studies of war and violence, 24-46. Glasgow: Cruithne Press

Walker, P.L. 1989. Cranial injuries as evidence of violence in prehistoric southern California. American Jol Physical Anthropology 80, 313-23

Walker, P.L. 1997. Wife beating, boxing, and broke skeletal evidence for the cultural patterning of vio Martin \& Frayer (eds) 1997, 145-80

Ward, J. 1915. St. Nicholas chambered t Glamorgan. Archaeologia Cambrensis 15, 253-3

Webb, S. 1995. Palaeopathology of Aboriginal Aus Cambridge: University Press

Webber, M. \& Ganiaris, H. 2004. The Chelsea Neolithic wooden artefact from the River Th London. In J. Cotton \& D. Field (eds), Toward: Stone Age: Aspects of the Neolithic in Sor England, 124-7. York: Council for British Arct Research Report 137

Wendorf, F. 1968. Site 117: a Nubian Final Pa graveyard near Jebel Sahaba, Sudan. In F. Wendc The Prehistory of Nubia, 954-95. Dallas: S Methodist University Press

Whitehead, N.L. 2002. Dark Shamans. Kanaimà Poetics of Violent Death. London: Duke Universi Whittle, A. 1977. Earlier Neolithic enclosures in no Europe. Proceedings of the Prehistoric Society 43,

Whittle, A. 1994. Excavations at Millbarrow I chambered tomb, Winterbourne Monkton, Wiltshire. Wiltshire Archaeology and Natural Magazine 87, 1-53

Whittle, A. 1996. Europe in the Neolithic: the cre new worlds. Cambridge: University Press

Whittle, A. 1997. Moving on and moving around: $\Lambda$ settlement mobility. In P. Topping (ed.), N Landscapes, 15-22. Oxford: Oxbow

Whittle, A. 2003. The Archaeology of People: dimer Neolithic life. London: Routledge

Whittle, A. \& Pollard, J. 1998. Windmill Hill caus enclosure: the harmony of symbols. In M. Edmon Richards (eds), Understanding the Neolithic of Western Europe, 231-47. Glasgow: Cruithne Pre؛ Whittle, A. \& Wysocki, M. 1998. Parc le Breo transepted long cairn, Gower, West Glamorgas contents and context. Proceedings of the Prt Society 64, 139-82

Willey, P. 1990. Prehistoric warfare on the Great Skeletal Analysis of the Crow Creek Massacre New York: Garland Publishing

Wilkinson, R.G. \& Wagenen, K.M. van. 1993. I against women: prehistoric skeletal evidenc Michigan. Midcontinental Journal of Archaeole 190-216

Whitley, J. 2002. Too many ancestors. Antiquity 76, Wysocki, M. n.d. Human skeletal remains from Neolithic mortuary monuments in southern Unpublished report on file with author

Wysocki, M. \& Whittle, A. 2000. Diversity, lifesty rites: new biological and archaeological evidenc British earlier Neolithic mortuary assemblages. $A$ : 74, 591-601 


\section{R. Schulting and M. Wysocki EVIDENCE FOR CRANIAL TRAUMA IN THE BRITISH NEOLITHIC}

$-76$

$\tau$ Thomas, J. 2003. In the kinship of cows: the :entrality of cattle in the earlier Neolithic of a Britain. In M. Parker Pearson (ed.), Food, and Identity in the Neolithic and Early Bronze -44. Oxford: British Archaeological Report S1117 aschner, K.L. \& Maschner, H.D.G. 1999. ing middlemen: western expansion and violent in the Subarctic. Ethnohistory 46, 703-43

A. 1932. Hunger and Work in a Savage Tribe. A nal Study of Nutrition among the Southern Bantu : Routledge

M.P., Schulting, R.J. \& Hedges, R.E.M. 2003. iift in diet at onset of Neolithic. Nature 425, 366 1986. The phenomenon of violence. In D. Riches be Anthropology of Violence, 1-27. Oxford: Ill

1, L. 1973. The Last of the Nuba. New York: \& Row

1997. Violence and gender in Italy. In Martin \& eds) $1997,111-44$

1-Mackay, R. 1987. The Neolithic causewayed re at Staines, Surrey: excavations 1961-63. 'ings of the Prehistoric Society 53, 23-128

1990. The human skeletal material. In A. Saville azleton North: the excavation of a Neolithic long f the Cotswold-Severn Group, 182-98. London: Buildings and Monuments Commission for

G. 1876. On the people of the long barrow Journal of the Anthropological Institute 5,

G. 1877. General remarks upon the series of iric crania. In W. Greenwell (ed.), British Barrows, 8. Oxford: Clarendon

R. 1980. Ilongot Headhunting 1883-1974. 1: University Press

ionwy, P. 2004. How the West was lost: a leration of agricultural origins in Britain, Ireland, uthern Scandinavia. Current Anthropology 45 nent), S83-S113

2002. Lithic artefacts from Neolithic causewayed ces: character and meaning. In G. Varndell \& P. ; (eds), Enclosures in Neolithic Europe, 91-105. Oxbow

, R. 1993. Ritual, Violence, and Creativity. In S. K. Narayan \& R. Rosaldo (eds), Creativity/ ology, 296-320. Ithaca: Cornell University Press I.W. \& Schmidt, B.E. 2001. Introduction: violent ries and violent practices. In B.E. Schmidt \& I.W. r (eds), Anthropology of Violence and Conflict, ondon: Routledge

R.J. 1998. Slighting the Sea: the bic-Neolithic Transition in Northwest Europe. ished Ph.D. thesis, Department of Archaeology, ity of Reading

R.J. 2004. An Irish Sea change: some implications Mesolithic-Neolithic transition. In V. Cummings Fowler (eds), The Neolithic of the Irish Sea: materiality and traditions of practice, 22-8. Oxford: Oxbow

Schulting, R.J. \& Wysocki, M. 2002. Cranial trauma in the British earlier Neolithic. Past 41, 4-6

Schwandner-Sievers, S. 2001. The enactment of 'tradition': Albanian constructions of identity, violence and power in times of crisis. In B.E. Schmidt \& I.W. Schröder (eds), Anthropology of Violence and Conflict, 97-120. London: Routledge

Selkirk, A. 1971. Ascott-under-Wychwood. Current Archaeology 24, 7-10

Sharples, N. 1991. Warfare in the Iron Age of Wessex. Scottish Archaeological Review 8, 79-89

Sharples, N.M. (ed.) 1991. Maiden Castle: excavations and field survey 1985-6. London: Historic Buildings and Monuments Commission for England

Sheridan, A. 1996. The oldest bow and other objects. Current Archaeology 149, 188-90

Smith, M.O. 1996. Parry fractures and female-directed interpersonal violence: Implications from the Late Archaic Period of west Tennessee. International Journal of Osteoarchaeology 6, 84-91

Smith, M.O. 1997. Osteological indicators of warfare in the Archaic period of the Western Tennessee Valley. In Martin \& Frayer (eds) 1997, 241-66

Smith, M.O. 2003. Beyond palisades: the nature and frequency of late prehistoric deliberate violent trauma in the Chickamauga Reservoir of East Tennessee. American Journal of Physical Anthropology 121, 303-18

Smith, O.C., Pope, E.J. \& Symes, S.A. 2003. Look until you see: identification of trauma in skeletal material. In D.W. Steadman (ed.), Hard Evidence: case studies in forensic anthropology, 138-54. Upper Saddle River: Prentice Hall Stallibrass, S. \& Huntley, J.P. 1996. Slim evidence: a review of the faunal and botanical data from the Neolithic of northern England. In P. Frodsham (ed.), Neolithic Studies in No-Man's Land, 35-42. Northern Archaeology 13/14

Standen, V.G. \& Arriaza, B.T. 2000. Trauma in the preceramic coastal populations of northern Chile: violence or occupational hazards? American Journal of Physical Anthropology 112, 239-49

Stewart, P.J. \& Strathern, A. 2002. Violence: theory and ethnography. London: Continuum

Strathern, A. 1992. Let the bow go down. In R.B. Ferguson \& N.L. Whitehead (eds), War in the Tribal Zone: expanding states and indigenous warfare, 229-50. Sante Fe: School of American Research Press

Teschler-Nicola, M., Gerold, F., Kanz, F., Lindenbauer, K. \& Spannagl, M. 1996. Anthropologische Spurensicherung: die Traumatischen und Postmortalen Veränderungen an den Linearbandkeramischen Skelettresten von Asparn/Schletz. Archäologie 7, 4-12

Thomas, J. 1988. The social significance of CotswoldSevern burial practices. Man 23, 540-59

Thomas, J. 1999. Understanding the Neolithic. London: Routledge

Thorpe, I.J. 1984. Ritual, power and ideology: a reconstruction of earlier Neolithic rituals in Wessex. In R. Bradley \& J. Gardiner (eds), Neolithic Studies: a review of 